\title{
Ozone production and hydrocarbon reactivity in Hong Kong, Southern China
}

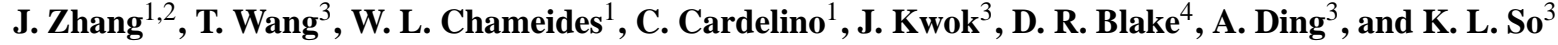 \\ ${ }^{1}$ School of Earth and Atmospheric Sciences, Georgia Institute of Technology, Atlanta, GA 30332, USA \\ ${ }^{2}$ School of Geography, Beijing Normal University, Beijing 100875, China \\ ${ }^{3}$ Department of Civil and Structural Engineering, The Hong Kong Polytechnic University, Hong Kong \\ ${ }^{4}$ Department of Chemistry, University of California, Irvine, CA 92697, USA
}

Received: 18 July 2006 - Published in Atmos. Chem. Phys. Discuss.: 25 September 2006

Revised: 14 December 2006 - Accepted: 17 January 2007 - Published: 30 January 2007

\begin{abstract}
Data obtained in Hong Kong during the Hong Kong and the Pearl River Delta (PRD) Pilot Air Monitoring Study in autumn 2002 are analyzed to unravel the relationship between ground-level ozone $\left(\mathrm{O}_{3}\right)$, pollution precursors, and cross-border transport. Ten ozone episodes, during which the hourly $\mathrm{O}_{3}$ concentration exceeded 100 ppbv in 9 cases and $90 \mathrm{ppbv}$ in one case, are subject to detailed analysis, including one case with hourly $\mathrm{O}_{3}$ of $203 \mathrm{ppbv}$, which is the highest concentration on record to date in Hong Kong. Combined with high-resolution back trajectories, $\mathrm{dCO} / \mathrm{dNO}_{\mathrm{y}}$ (the ratio of enhancement of $\mathrm{CO}$ concentration above background to that of $\mathrm{NO}_{\mathrm{y}}$ ) is used to define whether $\mathrm{O}_{3}$ is locally or regionally produced. Five out of the ten Hong Kong $\mathrm{O}_{3}$ episodes studied show a "pollution signature" that is indicative of impact from Guangdong Province. Examination of speciated volatile organic compounds (VOCs) shows that the reactivity of VOCs is dominated by anthropogenic VOCs, of which the reactive aromatics dominate, in particular xylenes and toluene. Calculations using a photochemical box model indicate that between $50-100 \%$ of the $\mathrm{O}_{3}$ increase observed in Hong Kong during the $\mathrm{O}_{3}$ episodes can be explained by photochemical generation within the Hong Kong area, provided that nitrous acid (HONO) is present at the concentrations derived from this study. An Observation-Based Model $(\mathrm{OBM})$ is used to calculate the sensitivity of the $\mathrm{O}_{3}$ production to changes in the concentrations of the precursor compounds. Generally the production of $\mathrm{O}_{3}$ throughout much of the Hong Kong area is limited by VOCs, while high nitric oxide (NO) concentrations suppress $\mathrm{O}_{3}$ concentration.
\end{abstract}

\footnotetext{
Correspondence to: T. Wang

(cetwang@polyu.edu.hk)
}

\section{Introduction}

The Pearl River Delta and adjoining Hong Kong metropolitan area of China, like virtually all other major urbanindustrialized regions of the world, suffers from photochemical smog characterized by the unhealthily high concentrations of ozone $\left(\mathrm{O}_{3}\right)$ and fine particles (Kok et al., 1997; Wang et al., 2001a; CH2M Hill, 2002; Wang, 2003). To design an effective strategy for controlling ground-level $\mathrm{O}_{3}$ pollution, it is critical to understand the $\mathrm{O}_{3}$ precursor relationships, i.e., the relative contributions of anthropogenic volatile organic compounds (VOCs) and nitrogen oxides $\left(\mathrm{NO}_{\mathrm{x}}=\mathrm{NO}+\mathrm{NO}_{2}\right)$ emissions to $\mathrm{O}_{3}$ production in Hong Kong, as well as local and regional contribution to ozone.

Traditionally, sophisticated air quality simulation models (AQMs, i.e. Emission Based Models - EBMs) have been used to determine whether a given airshed is $\mathrm{VOC}$ or $\mathrm{NO}_{\mathrm{x}}$ limited (Russell and Dennis, 2000, and papers cited therein). However, there are significant uncertainties in many aspects of EBMs (National Academy of Sciences (NAS), 1991; Oreske et al., 1994) including the emission inventories used to define the sources of $\mathrm{O}_{3}$ precursors (Pierson et al., 1990; Geron et al., 1994; Simpson, 1995; Guenther et al., 2000; Tan et al., 2004), the meteorological fields (Hanna et al., 1996; Kumar and Russell, 1996) and parameterizations used to simulate boundary layer dynamics (Kuklin and Seinfeld, 1995; Hanna et al., 1996). Further uncertainties may arise in the case of grid-based or Eulerian models for the assumption that point source emissions are dispersed throughout a grid instantaneously (Sillman et al., 1990).

A complementary approach to the use of EBMs is the application of observation-based analyses and/or models (Hidy, 2000), which uses measurements of ambient concentrations

Published by Copernicus GmbH on behalf of the European Geosciences Union. 


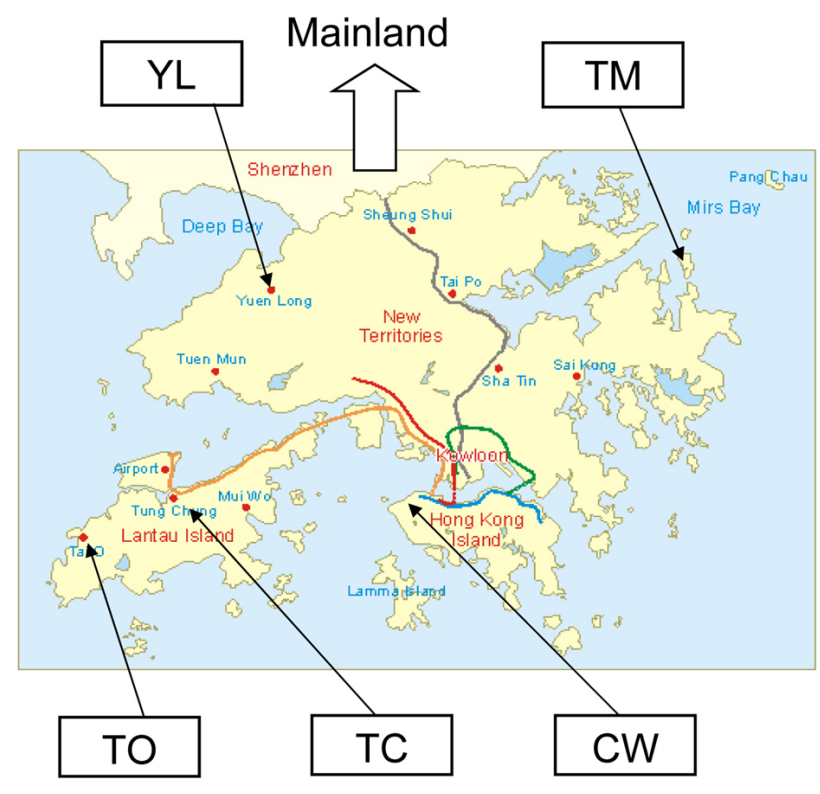

Plate 1. Map of the Hong Kong area showing the location of the sampling sites $(\mathrm{TO}=$ Tai $\mathrm{O}, \mathrm{TC}=$ Tung Chung, $\mathrm{CW}=$ Central Western, $\mathrm{YL}=$ Yuen Long, TM = Tap Mun). A description of the site characteristics is presented in the text. The arrow points in the direction of the major mainland source region.

of the chemical composition to check the applicability of physical/chemical mechanisms for the atmospheric processes (Calvert, 1976; Parrish et al., 1986; Chameides et al., 1990; McKeen et al., 1997) and for assessing the relative benefits of various proposed emission control strategies for regulatory purposes (Chameides et al., 1992; Cardelino and Chameides, 1995, 2000; Sillman, 1995; Sillman et al., 1997; Blanchard et al., 1999). Since the observation-based methods do not use emission inventories and often do not require the simulation of boundary layer dynamics, they avoid some of the uncertainties inherent in EBMs and thus provide a useful independent verification on the results obtained using EBMs.

In this study, a variety of observation-based analyses and models are used to analyze data collected during an intensive field campaign in the Hong Kong and the Pearl River Delta (PRD) Pilot Air Monitoring Study. The project was initiated in May 2002 and implemented over a 2-year period to better elucidate the emissions and processes responsible for the formation and accumulation of ground-level $\mathrm{O}_{3}$ in this area. Here we present the results of various observationbased analyses that were carried out (1) to identify the specific VOCs and VOC sources that contribute most to the formation of photochemical smog in Hong Kong, (2) to quantify the relative contributions of local production and pollutant import from other locations to the presence of photochemical smog, and (3) to assess, in a preliminary fashion, the relative benefits of various emission-control strategies for reducing the severity of photochemical smog.

\section{Experimental data}

Our analyses are based on data collected during an intensive sampling period from 1 October to 31 December, 2002 at five locations in Hong Kong: Central Western (CW), Yuen Long (YL), Tung Chung (TC), Tai O (TO), and Tap Mun (TM) (Plate 1). TO was operated by the Hong Kong Polytechnic University and the other four are monitoring sites operated by Hong Kong Environmental Protection Department (HK EPD).

\subsection{Meteorological conditions}

Hong Kong is situated on the South China coast and has a subtropical climate. The fall season is characterized by moderate temperatures, light winds out of the northeast and little precipitation. These conditions favor the transport of polluted air from the Asian continent to Hong Kong, as well as the accumulation of locally emitted pollutants in Hong Kong (Wang et al., 2001a). A detailed discussion of the meteorological conditions during the intensive 3-month field campaign of the Pilot Study is presented by Zhang et al. (2004). Compared to the long-term (1968-1990) mean, October 2002 was cloudier and wetter with dry air arriving occasionally which dispersed the clouds and brought on multiple-day periods conducive to the accumulation of air pollution in Hong Kong; the month of November was drier with fine weather and occasional strengthening of the northeast monsoon; the December was again cloudier and wetter than the long-term mean condition. During the whole study period there was usually a depression behind a high-pressure system over the South China Sea. The sunny and stagnant conditions associated with such high-pressure systems are favorable to the occurrence and accumulation of photochemical smog.

\subsection{Sites description}

Tai $\mathrm{O}\left(22.25^{\circ} \mathrm{N}, 113.85^{\circ} \mathrm{E}\right)$ is the Supersite for the study, where more intensive observations were performed than at the other sites. It is located in a sparsely populated coastal area with light local emissions, on northwestern Lantau Island roughly in the north-south centerline of the Pearl Estuary with Hong Kong's urban center of $32 \mathrm{~km}$ to the east and Macau/Zhuhai to the west at about the same distance (Plate 1). The area is surrounded by major urban centers in the PRD region, making it a good location to characterize local and regional emissions and the photochemical evolution of urban plumes. TO was selected as the location for the Supersite because available air quality data revealed that the highest ozone concentrations during air pollution episodes are generally found in the western part of Hong Kong with frequent occurrences of ozone episodes in autumn (Kok et al., 1997; Wang et al., 2001a). The measurement site is located inside an inactive barracks, at an elevation of $\sim 80 \mathrm{~m}$ 
above sea level. Longer term (15-month) data from this site show that various trace gases had maximum concentrations in winter (autumn for $\mathrm{O}_{3}$ ) and lowest mean values in summer (Wang et al., 2005; Simpson et al., 2006). Fine aerosol data in December 2002 was analyzed to show the impact of air masses from Hong Kong and the inner PRD on the particle levels at this site (Cheung et al., 2005). Pollution episodes observed in the earlier periods were examined by Wang and Kok (2003) and Wang et al. (2003), which revealed rapid changes in air-mass characteristics and different $\mathrm{CO} / \mathrm{NO}_{\mathrm{y}}$ ratios in air from Hong Kong and the inner PRD.

The Central-Western site $\left(22.27^{\circ} \mathrm{N}, 114.13^{\circ} \mathrm{E}\right)$ is located in a residential area on the northern western part of Hong Kong Island and near Hong Kong's busy "downtown" area (Plate 1). Yuen Long $\left(22.45^{\circ} \mathrm{N}, 114.02^{\circ} \mathrm{E}\right)$ is located in a new town in the northwestern part of New Territory Island in Hong Kong. It is about $15 \mathrm{~km}$ southwest of Shenzhen, a large and developing industrial city in Guangdong Province in South China. Tung Chung $\left(22.30^{\circ} \mathrm{N}, 113.93^{\circ} \mathrm{E}\right)$ is located on north Lantau Island about $10 \mathrm{~km}$ to the east of TO and about $3 \mathrm{~km}$ south of Hong Kong International airport on Chek Lap Kok. TC is located within a residential area in a new town, but adjacent to the highway and to railway lines that connect the airport to the other islands of Hong Kong. Tap Mun $\left(22.47^{\circ} \mathrm{N}, 114.33^{\circ} \mathrm{E}\right)$ is located on a remote island just off the northeast coast of Hong Kong. The surrounding area is rural and sparsely populated.

\subsection{Continuous measurements}

Ozone, $\mathrm{NO}, \mathrm{NO}_{2}, \mathrm{CO}$, and $\mathrm{SO}_{2}$ were measured continuously, together with particulate matter and meteorological parameters, at the HKEPD stations using instruments and quality assurance and control protocols which are very similar to those in US air-quality monitoring program (http: //www.epd-asg.gov.hk/english/backgd/backgd.php). A more extensive list of species and parameters measured at TO can be found in Zhang et al. (2004), and the techniques for measuring $\mathrm{O}_{3}, \mathrm{CO}, \mathrm{NO}, \mathrm{NO}_{\mathrm{y}}$, and $\mathrm{SO}_{2}$ have been described in Wang et al. (2003). Given the importance of measuring low concentrations of $\mathrm{NO}$ in determining $\mathrm{NO}_{\mathrm{x}}$-VOC chemistry regime (Cardelino and Chameides, 2000), we briefly summarize here the techniques for NO. A sensitive chemiluminescence instrument (with a limit of detection of $0.05 \mathrm{ppbv}$ ) was used at the Tai O supersite, while EPD stations adopted NO analyzers with a higher limit of detection of $0.4 \mathrm{ppbv}$. As shown later, these instruments were adequate to measure the afternoon low NO concentrations at the respective sites during the episode days.

Among these species/parameters, $\mathrm{O}_{3}, \mathrm{NO}, \mathrm{CO}$, and temperature, together with organic compounds, are the critical inputs to the Observation Based Model (OBM) used to assess the sensitivity of local $\mathrm{O}_{3}$ photochemical production to changes in the concentrations/emissions of $\mathrm{NO}_{\mathrm{x}}$ and VOC (Sect. 3.2). In addition, $\mathrm{CO}, \mathrm{SO}_{2}$ and $\mathrm{NO}_{\mathrm{y}}$ can be used as tracers of specific types of pollution and thus can provide valuable insights into the specific sources of pollutants that contribute to concentrations measured at the site (e.g. pollution from Hong Kong versus pollution from Guangdong). However, among the species needed for the OBM, CO was not measured at $\mathrm{CW}$ and $\mathrm{YL}, \mathrm{NO}$ was not measured at $\mathrm{YL}$, and $\mathrm{CO}$ measurements at TC and TM were made using instrumentation that lacked sensitivity to quantify $\mathrm{CO}$ concentrations when these concentrations are relatively low (i.e., $<1$ ppmv), because the EPD CO instruments were designed to monitor for compliance with the Hong Kong ambient air quality standard for $\mathrm{CO}(8-\mathrm{h}$ average of $8.7 \mathrm{ppmv})$. In order to carry out the OBM analysis for these sites, the required data were extrapolated from related measurements as described below. In the case of $\mathrm{CO}$, sufficiently sensitive determinations of the 24-h averaged $\mathrm{CO}$ concentrations at $\mathrm{CW}$, YL, TC, and TM were made using whole air samples collected from these sites (see Sect. 2.4 below). These 24-h averaged $\mathrm{CO}$ measurements were used to set the magnitude of the $\mathrm{CO}$ concentration that was input into the OBM, and the local continuous $\mathrm{CO}$ measurements were used to establish the diurnal variations. At $\mathrm{CW}$, where local, continuous $\mathrm{CO}$ measurements were not available, continuous $\mathrm{CO}$ measurements made at a neighboring site (Central, located about $1 \mathrm{~km}$ to the southeast of $\mathrm{CW}$ ) were used to set the diurnal variations. For YL, continuous $\mathrm{CO}$ measurements made at Tsuen Wan (located about $10 \mathrm{~km}$ to the south of YL) were used for the diurnal variations. Sensitivity calculations using constant $\mathrm{CO}$ concentrations at each of these sites throughout the diurnal cycle, based on the whole air sample analysis, indicate that the results of the OBM analyses were not significantly affected by these approximations.

At YL, the NO concentrations required in the OBM were estimated from the $\mathrm{NO}_{2}$ and related data obtained for YL using the chemical mechanism and iterative algorithms already contained in the OBM. Sensitivity calculations in which the NO concentrations were allowed to vary within reasonable limits at YL indicate that the conclusions reached using the OBM calculations were again not substantively affected by these approximations.

In addition, aerosol optical properties including light scattering and light absorption were measured during most of the measurement period at Tai $O$. These measurements were used to identify whether significant statistical correlations existed between ozone and particulate matter pollution.

\subsection{Collection of whole air samples and analysis for VOCs and $\mathrm{CO}$}

The ambient concentrations of $\mathrm{C}_{1}-\mathrm{C}_{10}$ hydrocarbons, $\mathrm{CO}$, and $\mathrm{C}_{1}-\mathrm{C}_{2}$ halocarbons at each of the sites were determined on selected days using whole air sampling canisters with subsequent analysis using gas chromatography. The samples were then shipped to and analyzed at the University of 


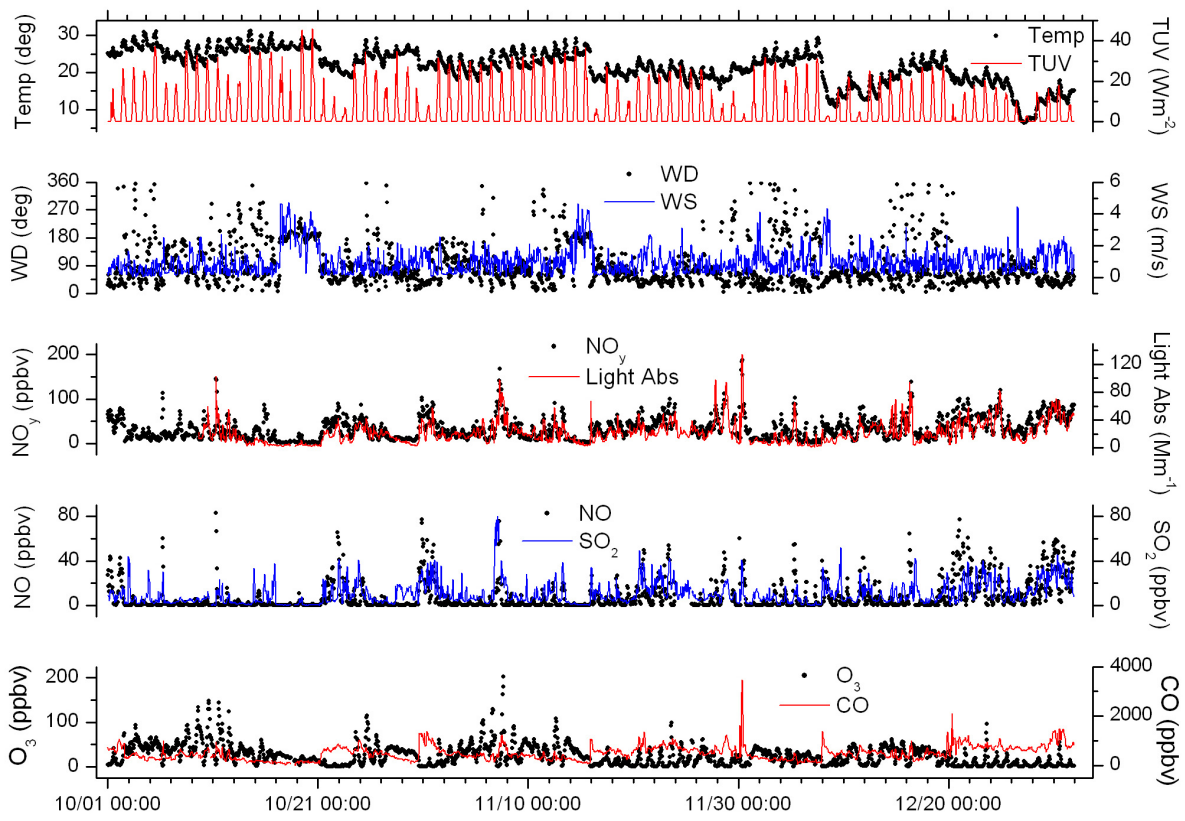

Fig. 1. Time series of measured $\mathrm{O}_{3}, \mathrm{CO}, \mathrm{NO}, \mathrm{NO}_{\mathrm{y}}, \mathrm{SO}_{2}$, temperature, total $\mathrm{UV}$, wind direction and speed, and light absorption from 1 October to 31 December 2002.

California - Irvine. The detailed descriptions of the analytical techniques are given in Colman et al. (2001).

As noted above, hourly speciated VOC and CO concentrations are needed as input to the OBM for a given site. However, the VOC analyses made for the 4 EPD sites were based on ambient whole air samples gathered over a 24-h period, and thus their use in the OBM required that estimates of hourly VOC concentrations at each site be derived. The derivation of diurnal VOC profile is presented in Sect. 3.2.2. In the case of the VOC concentrations at TO, while individual samples were generally collected at several times during the day, the frequency of collection was not hourly (see above). For this site, hourly VOC concentrations were estimated through a simple linear interpolation.

\section{Results and discussions}

\subsection{Data and diagnostic analysis}

\subsection{1 $\mathrm{O}_{3}$ pollution episodes}

Figure 1 illustrates the time series of measurements made at TO during the field measurement period. For the purposes of the analyses discussed here, we define an $\mathrm{O}_{3}$ episode day as a day when the peak one-hour averaged $\mathrm{O}_{3}$ concentration at TO (the site where $\mathrm{O}_{3}$ was generally the highest) exceeded $100 \mathrm{ppbv}$. (There were not any days during the measurement campaign when $\mathrm{O}_{3}$ exceeded $100 \mathrm{ppbv}$ at one of the other four sites but did not exceed 100 ppbv at TO, so this definition is inclusive.) Inspection of Fig. 1 reveals that during the campaign, $9 \mathrm{O}_{3}$ episode days were encountered. Of these 9, 4 occurred during a multiple-day episode spanning 912 October $\left(\mathrm{O}_{3}\right.$ maximum $\left.=149 \mathrm{ppbv}\right), 3$ occurred during a multiple-day episode spanning 5-7 November $\left(\mathrm{O}_{3}\right.$ maximum $=203$ ppbv). The 7 November episode day was especially interesting as the peak $\mathrm{O}_{3}$ on that day of $203 \mathrm{ppbv}$ is the highest $\mathrm{O}_{3}$ concentration ever reported for the Hong Kong/PRD region to date. The two other individual $\mathrm{O}_{3}$ episode days occurred on 25 October and 12 November.

Further inspection of Fig. 1 reveals that the $\mathrm{O}_{3}$ episode days occurred when the total UV was high, the wind speed was low, and the wind direction was generally from the north/northeast/northwest, which is consistent with previous observations in the area (Wang and Kwok, 2003; Wang et al., 2003). On some episode days $\mathrm{SO}_{2}$ or $\mathrm{NO}_{\mathrm{y}}$ was high (with concentrations higher than $80 \%$ of observation during the whole season) (e.g. 11 October and 7 November), but not on others (e.g. 9 October). CO was also generally high on episode days, for example 9-11 October, 25 October, and 5-7 November. Aerosol absorption was high on 10-11 October and 7 November. On 7 November, when $\mathrm{O}_{3}$ reached its record high of $203 \mathrm{ppbv}, \mathrm{SO}_{2}, \mathrm{NO}_{\mathrm{y}}, \mathrm{CO}$, TUV and light absorption were all relatively high. By contrast, note that on 30 November, $\mathrm{CO}, \mathrm{SO}_{2}, \mathrm{NO}_{\mathrm{y}}$, and aerosol absorption were all high and the wind direction was favorable for the import of $\mathrm{O}_{3}$ precursors into the Hong Kong area, and yet, probably because of low temperatures and overcast conditions (i.e., low total $\mathrm{UV}$ ), an $\mathrm{O}_{3}$ episode did not occur.

In the analyses presented here, we will focus on the aforementioned $9 \mathrm{O}_{3}$ episode days as well as an additional near- $\mathrm{O}_{3}$ 

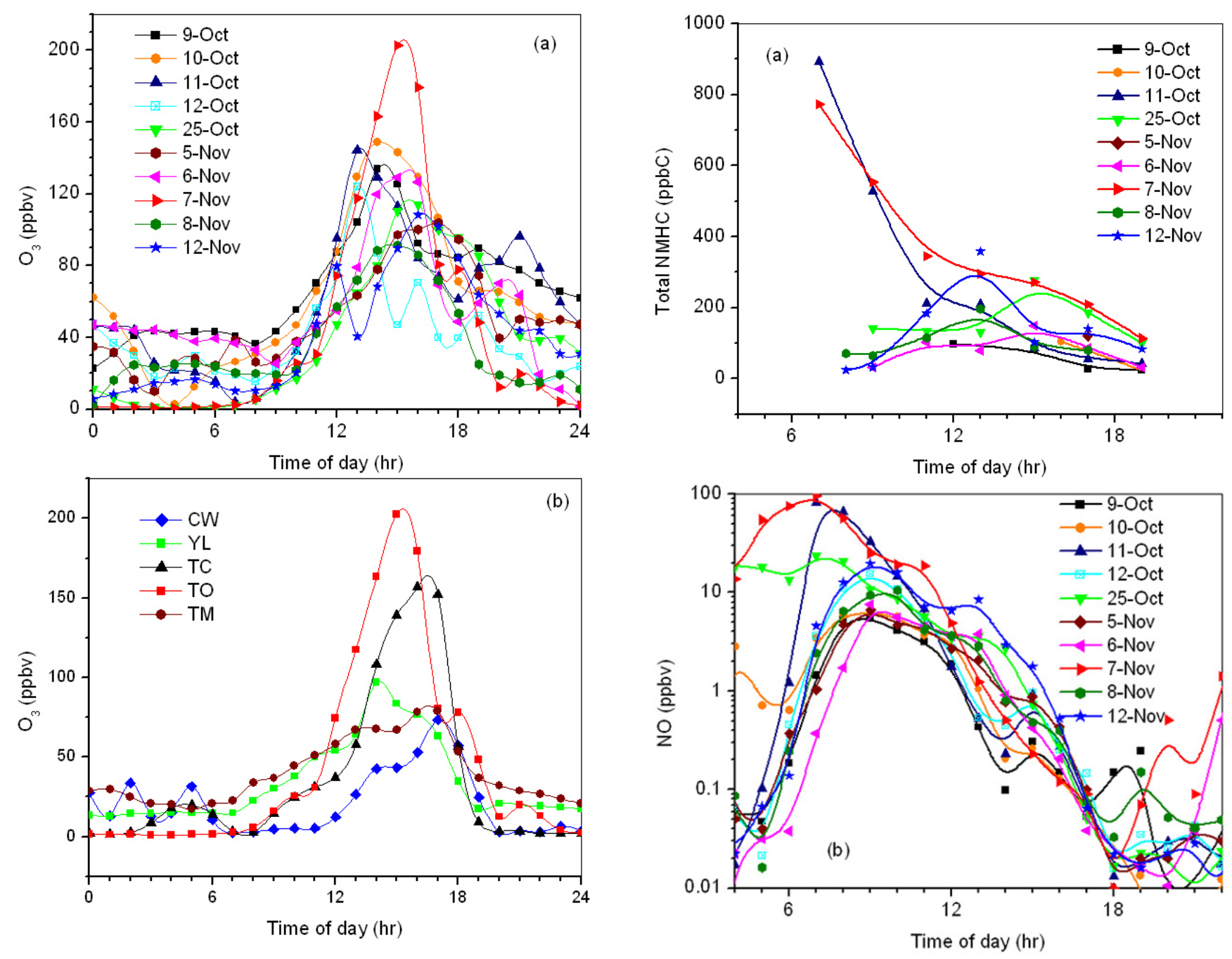

Fig. 2. Diurnal variations of $\mathrm{O}_{3}$ concentrations: (a) Observed at Tai O during episode days; (b) Observed at all five sites on 7 November 2002.

episode day ( 8 November) when $\mathrm{O}_{3}$ peaked at $91 \mathrm{ppbv}$ to see if there are any striking differences on this day as compared to the actual episode days. Relevant episode characteristics on each of these days are listed in Table 1. For example, VOC data were obtained at TO on all days but 12 October, and 7 November was the only day when VOC data were obtained at the EPD-operated sites as well as at TO. For this reason, and because the $\mathrm{O}_{3}$ recorded on 7 November was the highest on record for the area, the data gathered on this day are subjected to the most comprehensive analysis.

\subsubsection{Diurnal variations of $\mathrm{O}_{3}$ and related species}

Figure 2 a shows the diurnal $\mathrm{O}_{3}$ variations on the episode days at TO. As is typical of urban areas, $\mathrm{O}_{3}$ is low at night and in the morning and peaks during the afternoon. On 25 October and 7 November, $\mathrm{O}_{3}$ is almost zero at night and in early

Fig. 3. Diurnal variations of (a) nonmethane hydrocarbons and (b) NO observed at Tai $\mathrm{O}$ on the episode days.

morning coinciding very high levels of NO (see Fig. 3b) indicating a strong titration of $\mathrm{O}_{3}$ by NO. There are some notable features of the $\mathrm{O}_{3}$ variation at TO. First, $\mathrm{O}_{3}$ does not begin to increase until late in the morning, and secondly, $\mathrm{O}_{3}$ appears to peak early and begins to decline early in the afternoon, which is similar with the observations of Wang and Kwok (2003). This behavior could be attributed to high concentrations of NO (see later discussion), a short period of intense sunlight (the episodes are occurring well after the fall equinox), and transport of air masses of different chemical characteristics to the site (e.g. the afternoon transport patterns tend to bring air from the mainland).

Figure 2b shows the $\mathrm{O}_{3}$ concentrations at all five sites on 7 November. As is typical of the area and of all episodes encountered during the field campaign, $\mathrm{O}_{3}$ was highest on Lantau Island (TC, TO), and higher at TO than at TC. The 
Table 1. Days during the field campaign that were subjected to our analyses.

\begin{tabular}{llll}
\hline Date $^{(1)}$ & $\begin{array}{l}\text { Daily maximum 1-h O } \\
\text { (ppbv) at TO }\end{array}$ & Categorization $^{(2)}$ & Comment \\
\hline 9 October & 134 & $\mathrm{~L}$ & VOC at TO \\
10 October & 149 & $\mathrm{~L}, \mathrm{r}$ & VOC at TO \\
11 October & 144 & $\mathrm{~L}, \mathrm{r}$ & VOC at TO \\
12 October & 124 & $\mathrm{~L}, \mathrm{r}$ & No VOC data \\
25 October & 114 & $\mathrm{~L}$ & VOC at TO \\
5 November & 104 & $\mathrm{~L}$ & VOC at TO \\
6 November & 129 & $\mathrm{~L}$ & VOC at TO \\
7 November & 203 & $\mathrm{R}$ & VOC at all sites \\
8 November & 91 & $\mathrm{~L}, \mathrm{r}$ & VOC at TO \\
12 November & 108 & $\mathrm{~L}$ & VOC at TO \\
\hline
\end{tabular}

(1) All days except 8 November are $\mathrm{O}_{3}$ pollution episode days when the 1-h averaged $\mathrm{O}_{3}$ at $\mathrm{TO}$ exceeded $100 \mathrm{ppbv}$.

(2) $\mathrm{L}=$ local episode

$\mathrm{L}, \mathrm{r}=$ Local episode with some impact from the mainland

$\mathrm{R}=$ Regional episode with significant impact from the mainland

diurnal variations of $\mathrm{O}_{3}$ observed at the EPD-operated sites are similar to that observed at $\mathrm{TO}$ in that the $\mathrm{O}_{3}$ increase begins late in the morning. However, unlike TO, only the YL site also showed an $\mathrm{O}_{3}$ peak early in the afternoon; the TC, CW and TM sites showed peaks closer to 18:00. This might be attributed to the different characteristics of the sites.

Figure 3 illustrates the diurnal variations of total nonmethane hydrocarbons and $\mathrm{NO}$ at $\mathrm{TO}$ on the $\mathrm{O}_{3}$ episode days. There are two aspects of Fig. 3 that bear noting. The first is the generally large concentrations of NO that were encountered; daytime NO concentrations of several ppbv were the norm. Similarly high NO concentrations were also encountered at the other sites. As later discussion and analyses will show, these high NO concentrations directly lead to two important conclusions: (1) HONO concentrations in the early morning hours may be quite high and may significantly enhance $\mathrm{O}_{3}$ production; and (2) photochemical $\mathrm{O}_{3}$ production in the area during the episode days was strongly VOC-limited.

The second feature of note is the anomalously high early morning concentrations of $\mathrm{NO}$ and VOCs (as well as $\mathrm{CO}$ and aerosol absorption, not shown) on 11 October and 7 November. These high concentrations suggest that TO was subject to an unusually large amount of pollution during the early morning on these two days due to unusual weather conditions preventing dispersion of air pollutants and/or unusual nighttime transport patterns that brought more urban pollutants to TO.

\subsubsection{Transport characteristics of $\mathrm{O}_{3}$ episode days}

One of the key questions to be addressed in this study is the relative roles of local emissions and emissions transported from Guangdong Province in producing $\mathrm{O}_{3}$ pollution in Hong Kong. To address this question, we attempted to characterize the degree to which the air masses encountered in Hong Kong on the $\mathrm{O}_{3}$ episode days were impacted by air transported from Guangdong Province. Each day was assigned one of three possible categories: "L", indicating that the episode was largely local in character; "L, $\mathrm{r}$ ", indicating a local episode with some impact from Guangdong Province; and "R", indicated an episode with significant impact from Guangdong Province. As described below, two independent analyses were carried out to determine the appropriate category for each day. Only one of the episode days (7 November, the most severe episode) received an "R" categorization; 4 days $(10,11,12$ October, and 8 November) received an " $\mathrm{L}, \mathrm{r}$ " categorization; and the remaining 5 days received an "L" categorization (Table 1). Thus it would appear that both local and transported pollutants can act independently or in concert to bring about $\mathrm{O}_{3}$ pollution in the Hong Kong area, although the days with the highest Nonmethane Hydrocarbon (NMHC) and NO levels (7 November and 11 October; Fig. 3) were associated with some degree of regional influence.

Chemical Tracers: The ratio of the enhancement of $\mathrm{CO}$ over background values to the enhancement of $\mathrm{NO}_{\mathrm{y}}$ (i.e., $\mathrm{dCO} / \mathrm{dNO}_{\mathrm{y}}$ ) in an air mass is a useful diagnostic indicator of the relative influence of pollution from South Mainland China versus Hong Kong (Kok et al., 1997; Wang et al., 2001a, 2003), because the emission ratio of CO-to- $\mathrm{NO}_{x}$ from Guangdong and Hong Kong are so different; i.e., $\sim 15$ in Guangdong and $\sim 1$ in Hong Kong (Streets et al., 2003). Therefore high ratios are generally indicative of air masses from Mainland China and low ratios of air masses impacted by local Hong Kong emissions.

In the analysis presented here, $\mathrm{dCO} / \mathrm{dNO}_{\mathrm{y}}$ was calculated from the 1-h averaged $\mathrm{CO}$ and $\mathrm{NO}_{\mathrm{y}}$ measurements recorded at $\mathrm{TO}$ and subtracting the background $\mathrm{CO}$ and $\mathrm{NO}_{\mathrm{y}}$ concentrations from the observed concentrations. The background $\mathrm{CO}$ and $\mathrm{NO}_{\mathrm{y}}$ concentrations were estimated in two ways. A "seasonal" $\mathrm{dCO} / \mathrm{dNO}_{\mathrm{y}}$ was calculated using constant background $\mathrm{CO}$ and $\mathrm{NO}_{\mathrm{y}}$ concentrations of 211 and $3.37 \mathrm{ppbv}$, respectively. These concentrations are the mean values observed for marine air advecting over Hong Kong in the fall season (Wang et al., 2001b). A " 24 hourly" $\mathrm{dCO} / \mathrm{dNO}_{\mathrm{y}}$ was calculated using the minimum $\mathrm{CO}$ and $\mathrm{NO}_{\mathrm{y}}$ concentrations observed on that day. Figure 4 illustrates the diurnal variation in the " 24 hourly" ratios of $\mathrm{dCO} / \mathrm{dNO}_{\mathrm{y}}$ for each $\mathrm{O}_{3}$ episode day. (The "seasonal" ratios of $\mathrm{dCO} / \mathrm{dNO}_{\mathrm{y}}$ have the same results.) Note that 7 November is the only day with consistently high ratios during the late morning and early afternoon (consistent with its " $\mathrm{R}$ " categorization). The days 10 October, 11 October, 12 October and 8 November have transient spikes of high ratios and thus have "L, r" categorizations. On the other episode days, the ratios remained low throughout the photochemically important period and thus have "L" categorizations. 


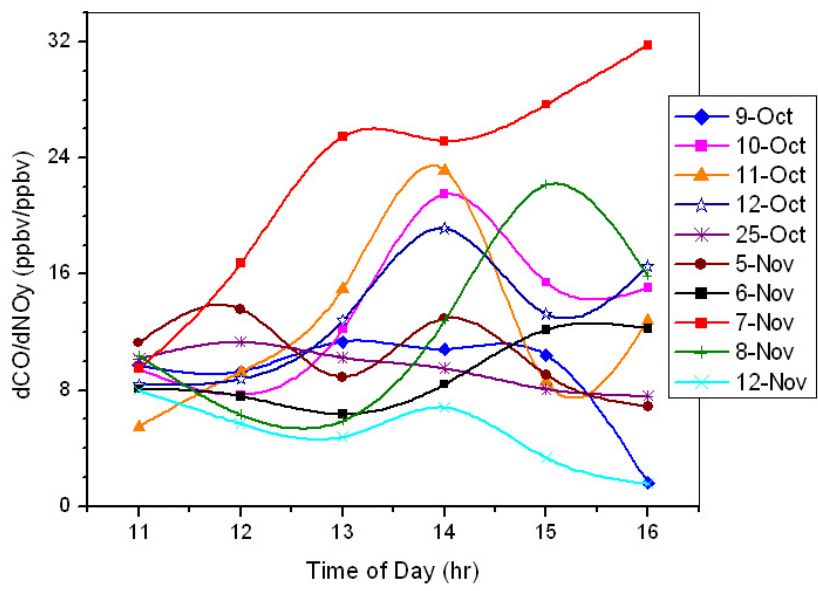

Fig. 4. Diurnal variations of " 24 hourly" ratio $\mathrm{dCO} / \mathrm{dNO}_{\mathrm{y}}$ at Tai $\mathrm{O}$ on ozone episode days. See the text for the method how " 24 hourly" ratio $\mathrm{dCO} / \mathrm{dNO}_{\mathrm{y}}$ is derived.

Back trajectories: As an independent check on the results obtained from the $\mathrm{dCO} / \mathrm{dNO}_{\mathrm{y}}$ ratios, back trajectories for air masses at TO during each of the $\mathrm{O}_{3}$ episode days were calculated. Figure 5 shows the trajectories for 10 October, 7 November, and 12 November illustrating a case of "L, r", "R", and "L", respectively. The back trajectories were calculated using the NOAA/ARL HYSPLIT4 model (Hybrid Single-Particle Lagrangian Integrated Trajectory model, version 4.6) driven by wind data with a $3-\mathrm{km}$ resolution calculated by NCAR/PSU Mesoscale Meteorological Model (MM5 version 3.6) (Ding et al., 2004). These plots generally corroborate the results from the ratio $\mathrm{dCO} / \mathrm{dNO}_{\mathrm{y}}$.

\subsubsection{Distribution and speciation of VOCs during the 7 November episode}

To facilitate the analysis of the distribution and speciation of VOCs observed at the various sites during the 7 November $\mathrm{O}_{3}$ pollution episode, we have grouped the $40+$ species measured at each site into three major types: $\mathrm{CO}$, anthropogenic hydrocarbons (AHC), and biogenic hydrocarbons (BHC), with BHC defined as isoprene and the pinenes. AHC are further divided into five sub-types according to their structure and reactivity with the $\mathrm{OH}$ radical in the atmosphere: reactive aromatics (R-AROM) encompassing all aromatics except benzene; reactive olefins (R-OLE), comprising all olefins except ethylene; alkanes with four or more carbons ( $>=\mathrm{C} 4$ ); ethylene (ETH); and the low reactivity hydrocarbons (LRHC) which include methane, ethane, propane, acetylene and benzene.

Based on the 24-h averaged concentrations of the major VOC groups and AHC subgroups measured at the five sites on 7 November, AHC clearly dominates over BHC at all sites (Fig. 6). Note in the figure that methane is not included in AHC since its reactivity is extremely low despite

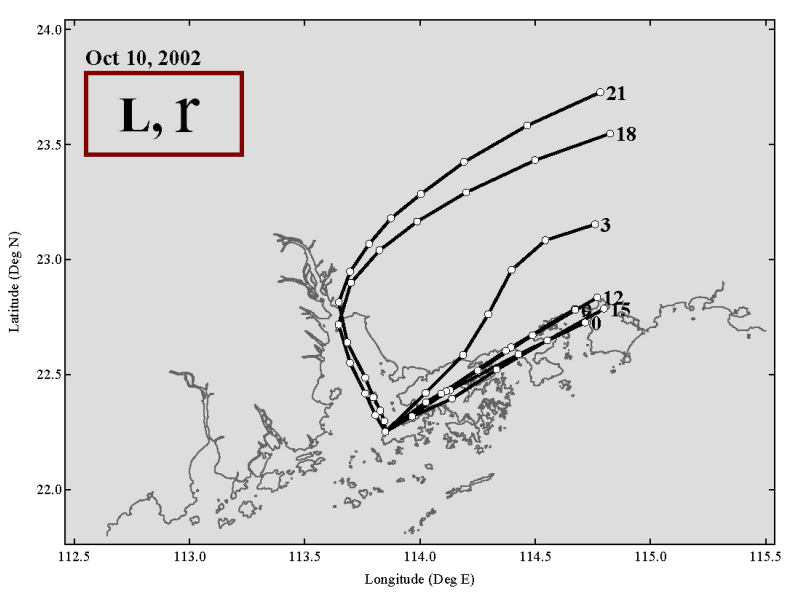

(a)

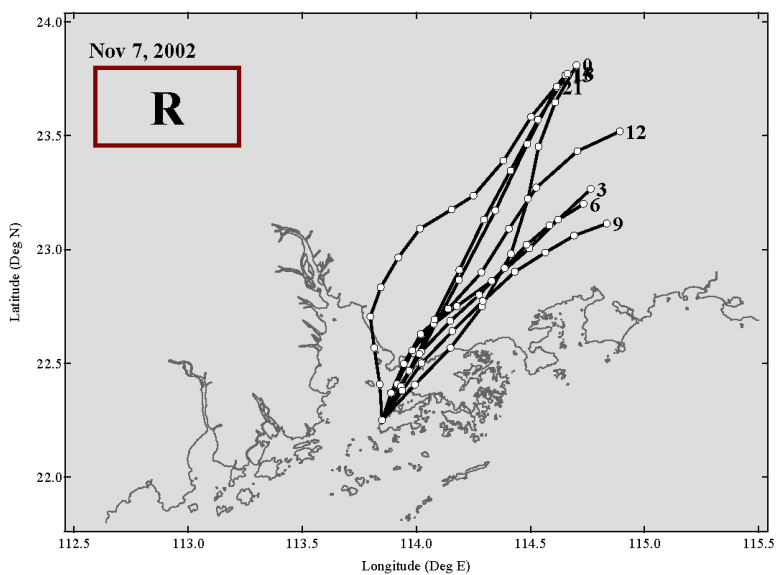

(b)

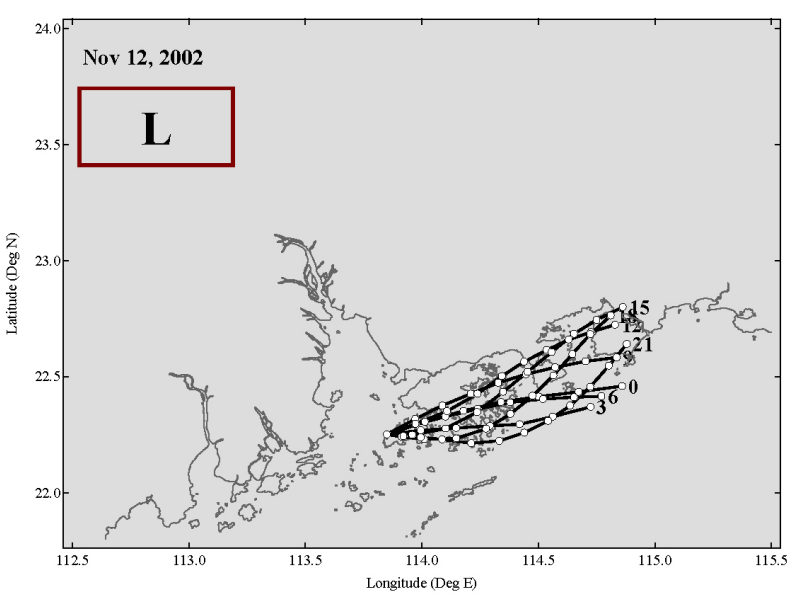

(c)

Fig. 5. Back trajectory clusters of air masses arriving at Tai $\mathrm{O}$ at different times on (a) 10 October, (b) 7 November, and (c) 12 November 2002. The number represent the arrival time of each trajectory and the open circles show hourly locations. $\mathrm{L}=$ local episode; $\mathrm{L}, \mathrm{r}$ = local episode with some impact from the mainland; $\mathrm{R}=$ regional episode with significant impact from the mainland.

its high concentration. The AHC levels occur in the order $\mathrm{YL}>\mathrm{TO}>\mathrm{TC}>\mathrm{CW} \gg \mathrm{TM}$. Although $\mathrm{TC}$ and $\mathrm{TO}$ are located 

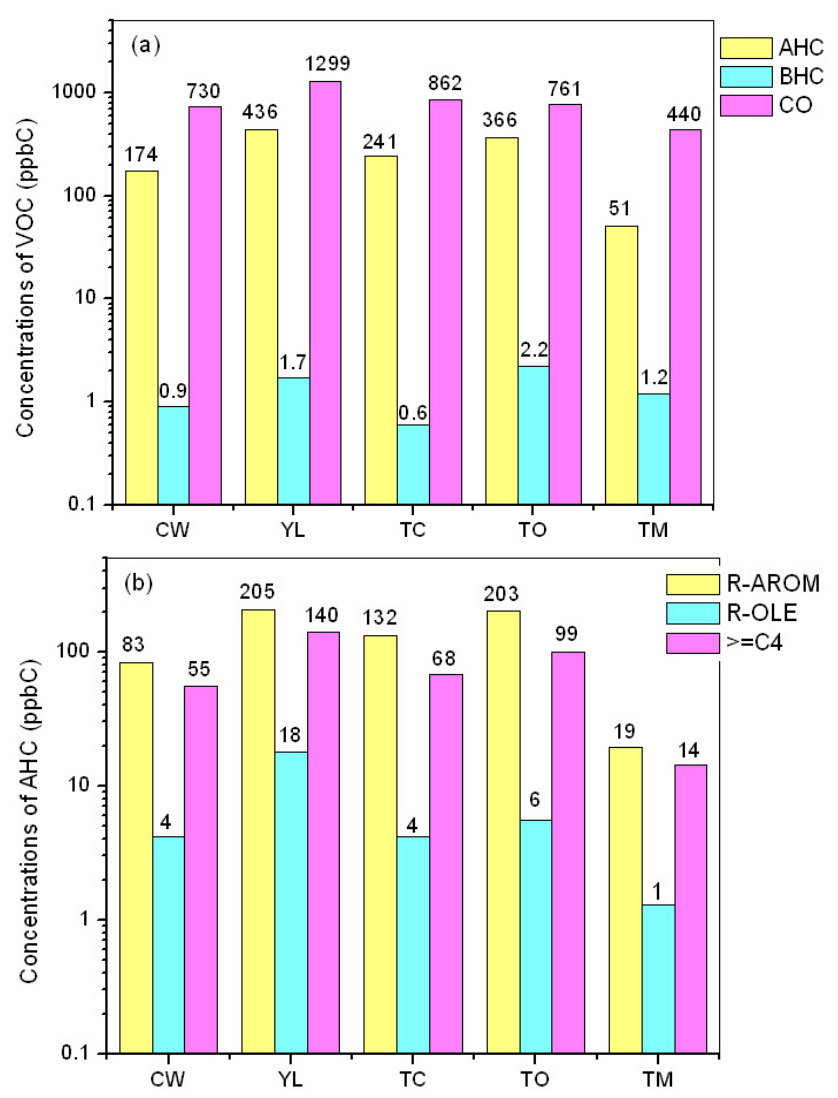

Fig. 6. VOC distribution (in unit of $\mathrm{ppbC}$ ) at all five sites on 7 November 2002: (a) Total VOCs grouped into AHC, BHC, and CO; (b) AHC subgroups R-AROM, R-OLE, and $>=\mathrm{C} 4$. Note for CW, YL, TC and TM, the values are 24-h averages; for TO, the values are averages of hourly measurements.

in the downwind direction of $\mathrm{CW}$ and $\mathrm{YL}$, the AHC levels at these two sites are higher than at $\mathrm{CW}$, and the AHC level at TO is comparable to that at YL. This suggests that there must be some other significant source of VOCs at TC and TO other than simply transport from the urban/industrial areas surrounding CW/YL. Within the AHC group, R-AROM is the dominant subgroup, which in turn is richest in xylenes and toluene, and to a lesser extent tri-methylbenzenes and ethyl-benzene. As was the case with AHC, R-AROM is highest at YL and TO followed by TC, CW and TM. The ETH levels (not shown in Fig. 6) occur in the same order as the AHC levels, but only contribute about $3 \%$ of the AHC concentrations.

\subsubsection{VOC reactivity}

Not all VOCs react at the same rate. In general the rate of reactivity among VOCs can vary as much as or even more than the concentrations of the VOCs in the atmosphere. To take both the concentration (on a $\mathrm{C}$ atom basis) and $\mathrm{OH}$-reactivity
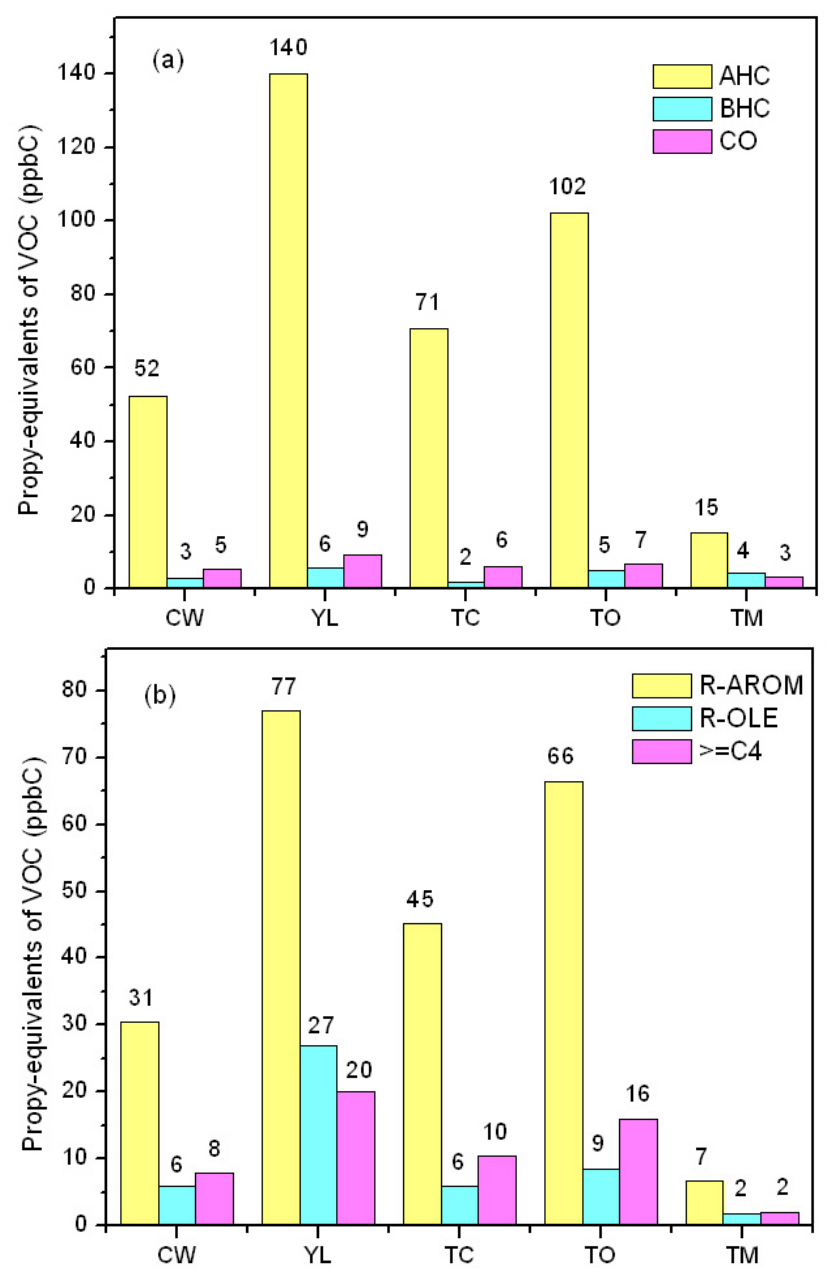

Fig. 7. Propy-equivalents (in unit of ppbC) of different VOC groups at all five sites on 7 November 2002: (a) Total VOCs grouped into AHC, BHC, and CO; (b) AHC subgroups R-AROM, R-OLE, and $>=\mathrm{C} 4$. Note for CW, YL, TC and TM, the values are 24-h averages; for TO, the values are averages of hourly measurements.

of each VOC into account, we use a reactivity scale called propy-equivalents (Chameides et al., 1992).

$$
\mathrm{C}_{\mathrm{i}}(\text { propy-equiv })=\mathrm{C}_{\mathrm{i}}(\text { observed }) \times\left[k_{\mathrm{OH}}(i) / k_{\mathrm{OH}}\left(\mathrm{C}_{3} \mathrm{H}_{6}\right)\right]
$$

where $C_{i}$ (propy-equiv) propy-equivalents (ppbC) of any VOC species $i$,

$\mathrm{C}_{i}$ (observed) observed concentration ( $\mathrm{ppbC}$ ) of species $i$, $k_{\mathrm{OH}}(i)$ reaction rate coefficient $\left(\mathrm{molec} / \mathrm{cm}^{3} / \mathrm{s}\right)$ of species i with radical $\mathrm{OH}$, and

$k_{\mathrm{OH}}\left(\mathrm{C}_{3} \mathrm{H}_{6}\right)$ reaction rate coefficient $\left(\mathrm{molec} / \mathrm{cm}^{3} / \mathrm{s}\right.$ ) of $\mathrm{C}_{3} \mathrm{H}_{6}$ with radical $\mathrm{OH}$.

In this formulation, the concentration (weighted by the number of carbons) of each VOC species is re-normalized by a factor that is proportional to its reactivity with $\mathrm{OH}$. The resulting reactivity is referred to as propy-equivalents because 


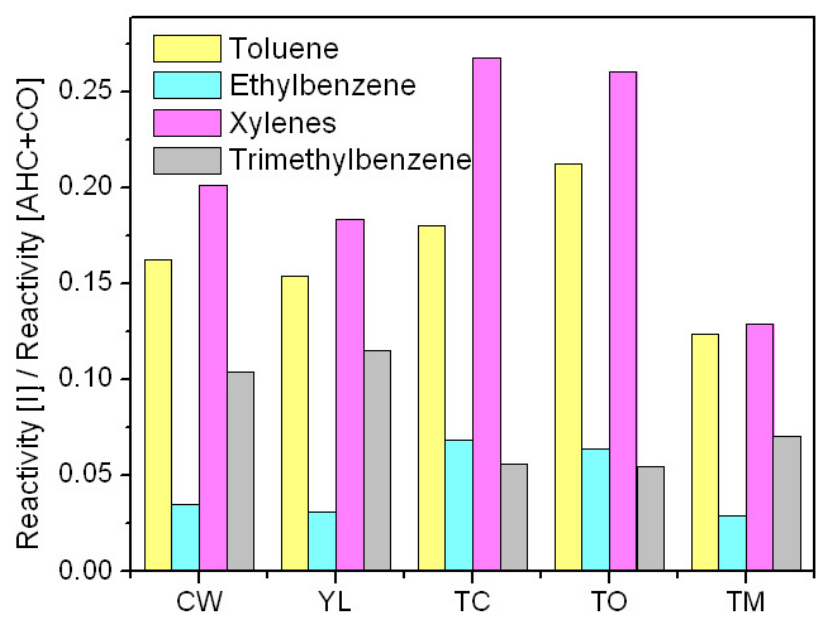

Fig. 8. Propy-equivalent reactivity fractions of different species to the total reactivity of anthropogenic VOCs and CO on 7 Novmeber 2002: Toluene, Ethylbenzene, Xylenes and Trimethylbenzene.

the normalization factor used is the rate constant for propylene with $\mathrm{OH}$. The choice of propylene is arbitrary and another normalization factor could be used with the same results.

Distribution of Reactivities on 7 November: Fig. 7a-b shows the propy-equivalents of different VOC groups at the five sites on 7 November, and Fig. 8 shows the relative contributions of different species to the total reactivity of anthropogenic VOCs and CO. In general the reactivity analyses reinforce the conclusions reached earlier on the basis of the VOC concentrations; i.e., AHC dominated over BHC, and RAROM was the most important AHC subgroup. The above result is based on 24-h average measurements of VOC at the four EPD sites and hourly measurements at TO during the daytime on 7 November 2002. Since BHC generally peaks at noon, to better compare the contribution of $\mathrm{AHC}$ and $\mathrm{BHC}$ to the reactivity during the daytime, we also used the derived diurnal VOC profile described in Sect. 3.2.2. The results show that even at noon, AHC still dominated over BHC with the highest contribution of $30 \%$ of BHC to the reactivity at TM. At other sites, BHC contributes less than $12 \%$ (not shown).

There are a number of additional insights that can be garnered from the propy-equivalents analysis. For example, even though the $\mathrm{CO}$ concentrations were greater than the total VOC concentrations at all sites (Fig. 6a), the total AHC reactivity was greater than that of $\mathrm{CO}$ at all sites (Fig. 7a). This suggests that AHC played a greater role in generating local $\mathrm{O}_{3}$ than $\mathrm{CO}$ though $\mathrm{CO}$ might have an impact on $\mathrm{O}_{3}$ formation on a regional scale because of its longer lifetime. Among the AHCs, R-AROM contributed most to the total anthropogenic reactivity at all sites, accounting for over $50 \%$ at CW, YL, TC and TO and close to $40 \%$ at TM. Of the species included in the R-AROM group the xylenes dominated, accounting for over $25 \%$ of the total reactivity of an-

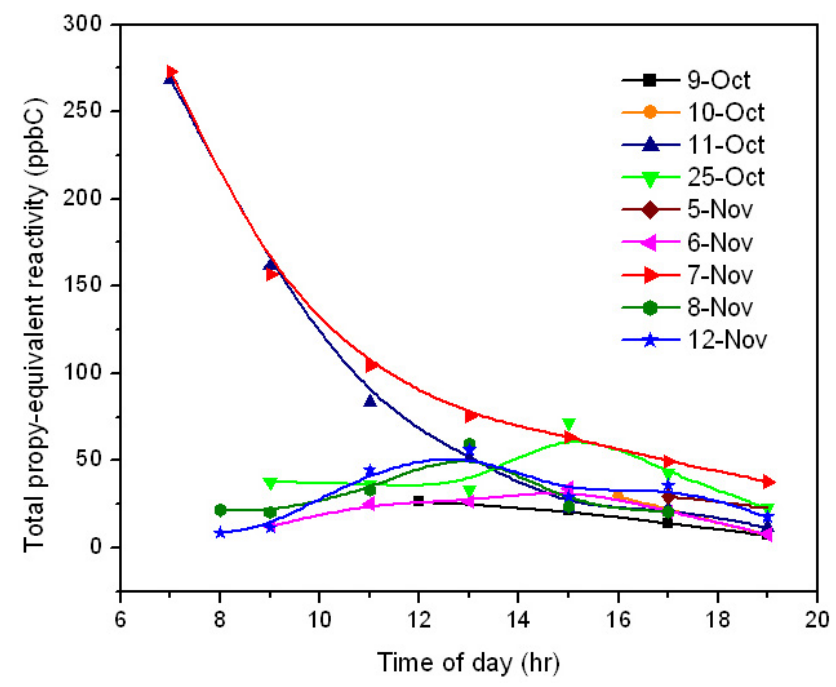

Fig. 9. Total propy-equivalent reactivity at Tai $\mathrm{O}$ on all episode days in which VOC data were available.

thropogenic VOCs (including CO) at TC and TO and over $18 \%$ of that at $\mathrm{CW}$ and YL. Toluene follows the xylenes in the R-AROM group (Fig. 8). At YL, R-OLE also made a significant contribution to the total reactivity from anthropogenic compounds (about 18\%). At CW, YL, TC, and TO, the contributions from $>=\mathrm{C} 4$ were also high (about 14\%). ETH and LRHC contributed much less to the total anthropogenic reactivity, with ETH contributed only 2-3\% and LRHC 2-4\% (not shown).

The results from TM are interesting because even though $\mathrm{TM}$ is a rural site, the influence of anthropogenic compounds appears to have been significant. While the contribution of $\mathrm{BHC}$ to the total anthropogenic reactivity was highest at TM (about 19\%), AHC and CO still dominated. The fraction of $\mathrm{CO}$ reactivity to the total anthropogenic reactivity was highest at TM; i.e. $\sim 17 \%$ as compared to about $6-9 \%$ at other four sites. This might be due to the fact that $\mathrm{CO}$ has a much longer lifetime than most VOCs. As more reactive VOCs are consumed by photochemistry, the relative importance of $\mathrm{CO}$ will tend to rise. Since TM is a rural site, one might expect $\mathrm{CO}$ would account for a higher fraction than at other sites. On the other hand, the contribution from R-OLE was relatively high at TM (about 10\%), and given the relative short lifetimes of R-OLE, this would appear to suggest that TM was directly influenced by local anthropogenic emissions.

Reactivity at Tai O: Fig. 9 shows the total propy-equivalent reactivity at Tai $\mathrm{O}$ on all episode days with VOC data. 11 October and 7 November are similar in that the early morning total propy-equivalent reactivity is much higher than that observed later during the day. As the morning progresses, however, the total propy-equivalent reactivity decreases rapidly and by noon the total reactivity on these two days was close to that on other episode days. As noted earlier, the anomalous 
behavior on 11 October and 7 November may reflect the presence of unusual meteorological conditions that caused the early-morning accumulation of pollutants at the TO site. Similar to the situation for 7 November, AHC dominated the total reactivity on all the episode days, and R-AROM was the most important subgroup of AHC (not shown). The 8 November episode is not significantly different from other episode days with regard to the characteristics of NO and VOCs.

\subsection{Ozone production and relative incremental reactivity}

In this section we present the results of our application of the Observation Based Model (OBM, Cardelino and Chameides, 1995) to the data collected at each of the five sites on the 7 November episode and at TO on all episode days. We begin with a brief overview of the OBM.

\subsubsection{Introduction to OBM}

The OBM uses the concentrations of primary hydrocarbons, $\mathrm{NO}, \mathrm{CO}$ and $\mathrm{O}_{3}$, as well as meteorological data measured as a function of time at a given location as input for a coupled set of photochemical box models that calculates the total amount of ozone that is photochemically produced during the daytime at that location based on Carbon-Bond IV mechanism (Cardelino and Chameides, 1995). The model also calculates the sensitivity of the $\mathrm{O}_{3}$ production to changes in the concentrations of the precursor compounds, i.e. Relative Incremental Reactivity (RIR). Since the production of $\mathrm{O}_{3}$ is related to the concentration of $\mathrm{O}_{3}$ at the site, and the concentration of a precursor is essentially linearly related to its emissions, RIR can be used to assess a given emission reduction on $\mathrm{O}_{3}$ concentrations at a site without detailed knowledge of the emissions.

Internal tests can be carried out to confirm that the application of the OBM to a given dataset is appropriate. One test is to assess the consistency of the RIRs across multiple sites and/or multiple days. For example, if the standard error of the mean for the area-averaged RIRs defined in the OBM is relatively small, the calculated RIRs are more likely to be robust. Another test is to consider the magnitude of the ozone production calculated by the OBM at each site and compare it to the increment of $\mathrm{O}_{3}$ observed at the site during the episode. If the calculated $\mathrm{O}_{3}$ production is similar in magnitude to the observed increment, it suggests that the RIR explains a significant portion of the amount of $\mathrm{O}_{3}$ that appeared at the site and is therefore relevant to policymaking decisions with regard to emission control strategies. As noted earlier, because the OBM uses observed concentrations, it is an observation-based as opposed to an emissionbased model. It complements emission-based models as part of a weight-of-evidence approach to air quality control.

\subsubsection{Deduction of hourly VOC profiles}

Since the VOC data at the four EPD sites are 24-h averages, it was necessary to derive time-dependent concentrations from these averages for use in the OBM. The method for accomplishing this is based on the entraining Eulerian box model (Seinfeld and Pandis, 1997). Assuming the atmosphere in the area of interest is well-mixed, the concentration of a species is determined by its emissions, chemical reactions, deposition (dry/wet), advection, and vertical entrainment. Equations $(2 a-b)$ give the resulting rate of change with time in the concentration of species $i$ :

$$
\begin{aligned}
& \frac{d c_{i}}{d t}=\frac{q_{i}}{H(t)}+R_{i}-\frac{v_{d, i}}{H(t)} c_{i}+\frac{c_{i}^{0}-c_{i}}{\tau_{r}} \quad \text { for } \frac{d H}{d t} \leq 0 \\
& \frac{d c_{i}}{d t}=\frac{q_{i}}{H(t)}+R_{i}-\frac{v_{d, i}}{H(t)} c_{i}+\frac{c_{i}^{0}-c_{i}}{\tau_{r}}+\frac{c_{i}^{a}-c_{i}}{H(t)} \frac{d H}{d t} \\
& \text { for } \frac{d H}{d t}>0
\end{aligned}
$$

where $c_{i}$ concentration $\left(\mathrm{mol} \mathrm{m}^{-3}\right)$ of species $i$,

$q_{i}$ emission rate $\left(\mathrm{mol} \mathrm{m}^{-2} \mathrm{~s}^{-1}\right)$ of species $i$ per unit area,

$H(t)$ mixing height $(\mathrm{m})$ as a function of time $t$,

$R_{i}$ chemical production/destruction rate $\left(\mathrm{mol} \mathrm{m}^{-3} \mathrm{~s}^{-1}\right)$ of species $i$,

$v_{d, i}$ dry/wet deposition rate $\left(\mathrm{m} \mathrm{s}^{-1}\right)$ of species $i$ (assumed to be zero for all the hydrocarbons),

$c_{i}^{0}$ background concentration $\left(\mathrm{mol} \mathrm{m}^{-3}\right)$ of species $i$,

$\tau_{r}$ residence time (s) of air over the area (which is the ratio of the length of the box to the prevailing wind speed), and

$\mathrm{c}_{i}^{a}$ concentration $\left(\mathrm{mol} \mathrm{m}^{-3}\right.$ ) of species $i$ above the boundary layer (assumed to be zero for all the hydrocarbons).

For our purposes, the advection term $\left(c_{i}^{0}-c_{i}\right) / \tau_{r}$ in Eqs. (2a-b) is combined with the emission term $q_{i} / H(t)$. Equations $(2 \mathrm{a}-\mathrm{b})$ are solved using Gear's backward differentiation formula (e.g., see Jacobson, 1999).

Since emission rates for the different VOCs and their chemical destruction rates are unknown (in the latter case because $\mathrm{OH}$ is unknown), we adopt an iterative approach to determine the hourly variations in the VOC species, along with their emission and destruction rates on the basis of their 24-h averaged concentrations and other inputs. We begin by assuming an initial $\mathrm{OH}$ profile and an emission rate for the VOCs, then calculate the time variation in the VOC species. The resulting 24-h averaged VOC concentrations thus calculated are compared to the observed 24-h average concentrations, and the emission rates are appropriately scaled to bring the calculated 24-h averages in line with the observed averages. A new $\mathrm{OH}$ profile is calculated on the basis of the VOC concentrations, and the process is repeated until convergence is obtained. In the results presented a $2 \%$ agreement is used as the basis for establishing consistency.

In addition to calculating the diurnal VOC profiles, this approach is also used to calculate the diurnal profiles in HONO, 
formaldehyde and higher aldehydes - species that were not observed during the field campaign but can impact the OBM results. These calculations and their implications are discussed in Sect. 3.2.3.

Emission Rates: The annual emissions of speciated anthropogenic VOCs from the NASA TRACE-P project (Streets et al., 2003) were used to set the initial VOC emission rates of the VOCs. The diurnal variations in the anthropogenic VOC emissions were estimated on the basis of the source type: industry and power generation were assumed to have no diurnal variation; domestic sources were kept constant during the daytime and set to 0 at night (09:00 p.m.05:00 a.m.); and mobile emissions were assigned a diurnal variation that differed as a function of day of the week (Cardelino, 1998). The diurnal variations of biogenic VOCs (isoprene, $\alpha$-pinene and $\beta$-pinene) were estimated considering the temperature and solar radiation.

Mixing Height Profile: The mixing height was estimated based on the principle that heat transferred from the surface to the atmosphere results in convection, vigorous vertical mixing, and establishment of a dry-adiabatic lapse rate (Holzworth, 1967). Here upper air soundings and hourly temperature were used to compute morning and afternoon mixing heights. The upper air soundings are reported by National Climate Data Center (NCDC) and available at the NOAA website (http://raob.fsl.noaa.gov/). We followed the approach of Holzworth (1967) with the exception that $2^{\circ} \mathrm{C}$ instead of $5^{\circ} \mathrm{C}$ was used to account for the temperature difference between rural and urban environments and for some initial surface heating just after sunrise while calculating the morning mixing height, since Hong Kong has a latitude of $22.32^{\circ} \mathrm{N}$ and the daily temperature difference between different areas is probably not as much as that at mid-latitudes. The hourly mixing height profiles were obtained by interpolating between the morning and afternoon mixing heights, considering that the mixing height increases rapidly after sunrise and slowly in early afternoon until it reaches the afternoon mixing height.

The diurnal variations in the total VOC reactivity at the 4 EPD sites on 7 November were therefore derived through the above method and illustrated in Fig. 10. Encouraging similarity is found between the calculated profile at YL and the observed profile at TO (two sites with similar average reactivities), and the inferred VOC diurnal profiles are utilized for OBM calculations presented below.

\subsubsection{OBM-calculated net $\mathrm{O}_{3}$ production}

In principle, the $\mathrm{O}_{3}$ that appears at a given site during a pollution episode is due to local photochemical production plus the transport of $\mathrm{O}_{3}$ that has been produced elsewhere. However, the OBM only calculates the $\mathrm{O}_{3}$ produced locally and/or in air masses with similar chemical compositions as that found locally. As a result the RIR functions calculated by the OBM only pertain to the $\mathrm{O}_{3}$ produced locally; i.e.,

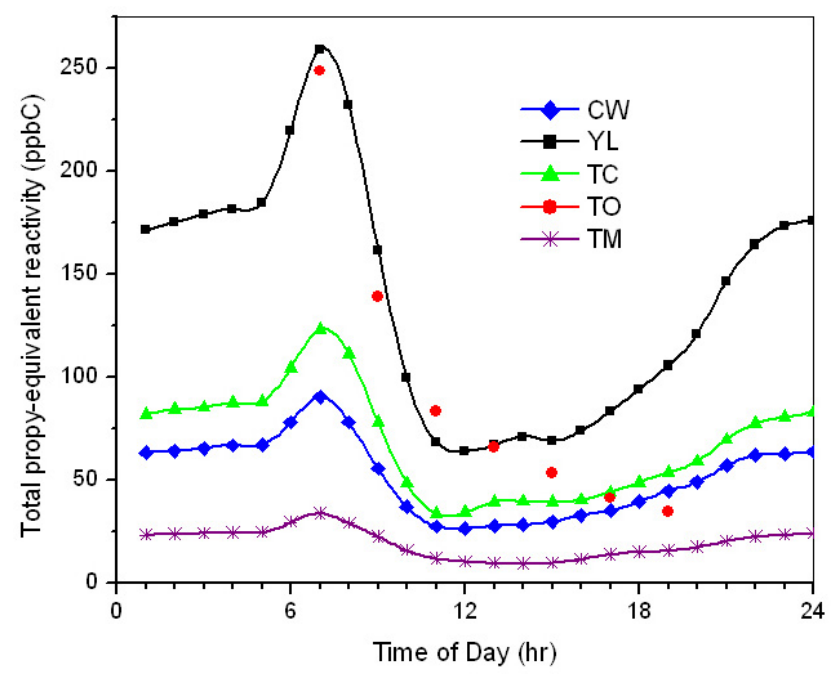

Fig. 10. Inferred diurnal profile of total reactivity from VOCs at $\mathrm{CW}, \mathrm{YL}, \mathrm{TC}$ and TM and the measured reactivity profile of VOC at TO on 7 November 2002.

they represent estimates of the sensitivity of the $\mathrm{O}_{3}$ produced locally to changes in precursor concentration/emissions, and not of the $\mathrm{O}_{3}$ that had been transported to the site. If local production represents a significant portion of the total $\mathrm{O}_{3}$ increase (or increment) experienced in the area, then this feature of the OBM does not represent a significant limitation. On the other hand, if local production is much smaller than the $\mathrm{O}_{3}$ increment, then the RIR functions calculated by the OBM are of limited utility. In this section we examine this issue by comparing the net photochemical production $\mathrm{O}_{3}$ calculated by the $\mathrm{OBM}$ at each site with the actual $\mathrm{O}_{3}$ increment observed at each site over the course of the episode day.

The observed $\mathrm{O}_{3}$ increment is defined here as the difference between the peak $\mathrm{O}_{3}$ concentration and the early morning $\mathrm{O}_{3}$ concentration. Figure 11a-b illustrates the modelcalculated net $\mathrm{O}_{3}$ production and the observed $\mathrm{O}_{3}$ increment at each of the sites on 7 November and at TO for all episode days, with and without early morning HONO and aldehydes (see discussions below). In general the $\mathrm{O}_{3}$ increment calculated by the OBM agreed well with observations (within 22\%) at all sites on 7 November, with the exception of TC (Fig. 11a). At TO, the agreement between the OBM and observations ranged from excellent $(<10 \%)$ during the 11 October and 7 November episodes to much poorer $(58 \%-75 \%)$ during the 6 and 12 November episodes (Fig. 11b). Generally between $50-100 \%$ of the $\mathrm{O}_{3}$ increase observed in Hong Kong during the $\mathrm{O}_{3}$ episodes can be explained by photochemical generation within the Hong Kong area. When HONO and aldehydes were omitted from the OBM the agreement with observations significantly deteriorated (Figs. 11a-b). These latter results suggest that early morning HONO and aldehydes concentrations were significant (as estimated by the OBM), and as a result of the 

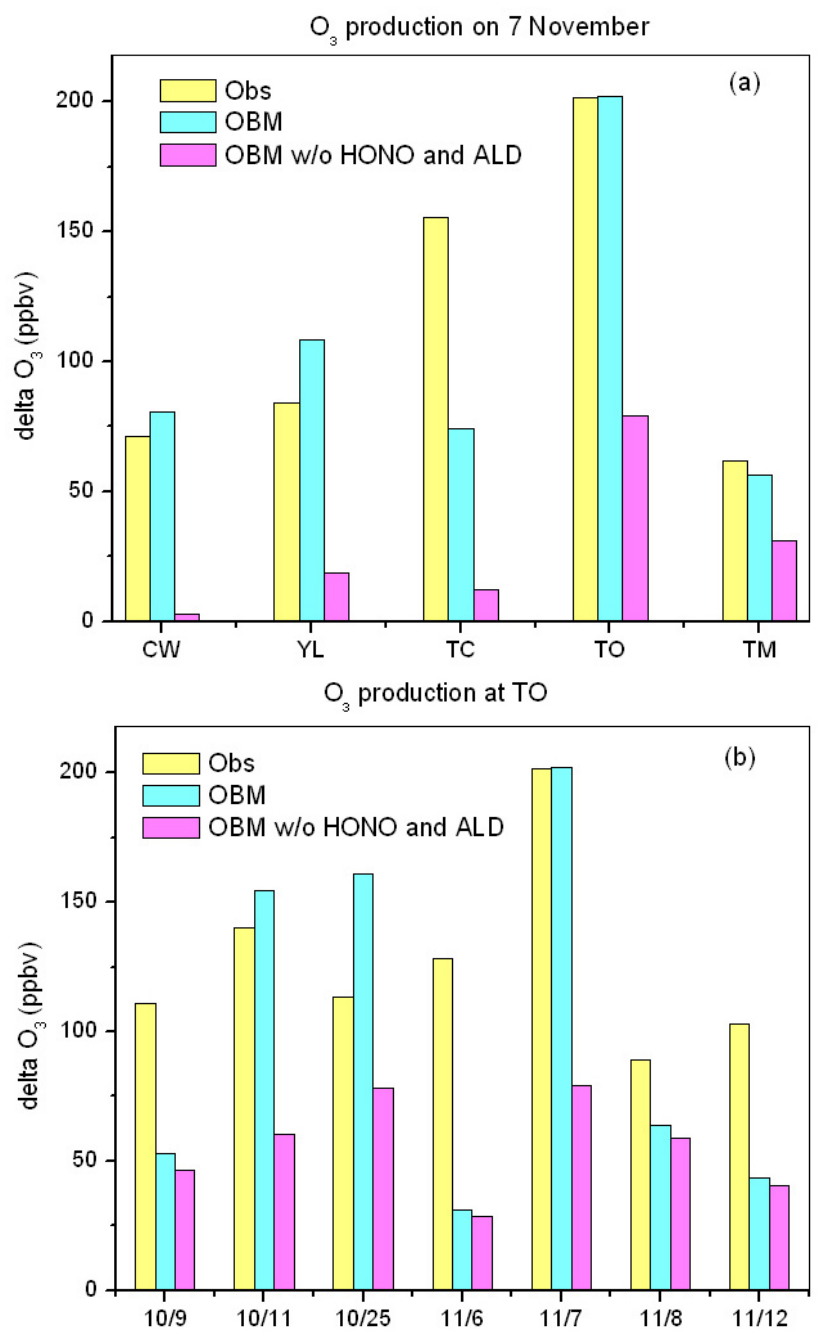

Fig. 11. Comparison of net photochemical $\mathrm{O}_{3}$ production calculated by the $\mathrm{OBM}$ with the observed $\mathrm{O}_{3}$ increments: (a) all sites on 7 November; and (b) Tai $\mathrm{O}$ on episode days. Results are shown for OBM calculations with and without early morning HONO and aldehydes (see text).

$\mathrm{OH}$ produced by these compounds in the early morning, the OBM was able to account for much/most of the ozone increments observed during episode days when HONO and aldehydes were included. Exceptions to the latter conclusion are TC on 7 November and TO on 9 October, 6 November, and 12 November when the calculated $\mathrm{O}_{3}$ production was significantly less than the observed increment even with early morning HONO and aldehydes included.

The Role of HONO and Aldehydes in Early Morning Chemistry: Previous investigators have found that the presence of HONO and/or aldehydes in the urban atmosphere in the early morning hours can significantly enhance the amount of $\mathrm{O}_{3}$ produced over the course of the day (Jenkin et al., 1988; Alicke et al., 2002, 2003; Finlayson-Pitts et al., 2003). HONO and aldehydes are fairly reactive and as a result their concentrations are usually fairly small during most of the daylight hours. However, at night, in the absence of sunlight and $\mathrm{OH}$, their concentrations can accumulate if sufficient sources of these compounds are present. Then, in the early morning when the sun first appears, they can be rapidly photolyzed; one product of this photolysis and subsequent reactions is $\mathrm{OH}$. Because other sources of $\mathrm{OH}$ (e.g., $\mathrm{O}_{3}$ photolysis) tend to be small in the early morning, HONO and aldehyde photolysis can represent a significant early-morning source of $\mathrm{OH}$, and this source can jump-start the photochemical reactions that lead to $\mathrm{O}_{3}$ production. The net result is more $\mathrm{O}_{3}$ production over the entire course of the day.

HONO and aldehydes were not measured during the field campaign and thus could not be specified in the OBM. We therefore carried out two sets of OBM calculations: in the calculations labeled "OBM w/o HONO and ALD" the concentrations of $\mathrm{HONO}, \mathrm{H}_{2} \mathrm{CO}$, and higher aldehydes in the morning were set to zero and allowed to accumulate in the model calculation; in the standard OBM calculations we allowed the OBM to estimate the early morning HONO, $\mathrm{H}_{2} \mathrm{CO}$, and aldehyde concentrations using the iterative process described in Sect. 3.2.2. In these calculations, we assumed that HONO was produced at night via a heterogeneous reaction involving $\mathrm{NO}_{\mathrm{X}}$ :

$2 \mathrm{NO}_{2}+\mathrm{H}_{2} \mathrm{O} \stackrel{\text { surface }}{\longrightarrow} \mathrm{HONO}+\mathrm{HNO}_{3}$

We further assumed a mixing height dependent rate constant following Harrison et al. (1996):

Rate Constant for HONO Production =

$$
\frac{3.36 \times 10^{-2}}{\text { Mixing Height }(\mathrm{m})}\left(\mathrm{min}^{-1}\right)
$$

Nighttime losses of HONO include dry deposition (with a rate constant of 1.2/mixing height (m) in units of $\min ^{-1}$ ).

The resulting diurnal variations in $\mathrm{HONO}$, formaldehyde and higher aldehydes calculated by the OBM at TO on 7 November are shown in Fig. 12a. Note the high HONO concentrations (of $\sim 10 \mathrm{ppbv}$ ) just before sunrise. As the sun comes out, however, HONO starts to photolyze and its concentration rapidly drops to sub-ppbv levels. However, as illustrated in Fig. 12b, the photolysis of HONO in the early morning represents a major source of $\mathrm{OH}$ in the OBM calculations, and, as a result, early morning $\mathrm{OH}$ concentrations are significantly enhanced (Fig. 12c). Inspection of the figures reveals that although the concentrations of formaldehyde and higher aldehydes are higher than HONO, their impact on $\mathrm{OH}$ production is relatively small. In addition, after $\sim 1100 \mathrm{~h}$, HONO concentrations have fallen sufficiently and $\mathrm{O}_{3}$ photolysis takes over as the dominant source of $\mathrm{OH}$. Alicke et al. (2002, 2003) also found a larger contribution of the HONO photolysis to the $\mathrm{OH}$ budget compared to the photolysis of formaldehyde $(\mathrm{HCHO})$ and $\mathrm{O}_{3}$ in the early hours of the morning based on studies in Milan and Berlin. 
Similar results are achieved at $\mathrm{CW}, \mathrm{YL}$, and TC on 7 November (not shown), suggesting that HONO played an important role in the early morning chemistry provided that HONO was present at the concentrations derived from the OBM calculations. Early-morning HONO concentrations of $\sim 10 \mathrm{ppbv}$ in the Hong Kong area do not seem unreasonable given that $\mathrm{Hu}$ et al. (2002) observed peak early-morning HONO levels approaching 12 ppbv in nearby Guangzhou in June 2000. Nevertheless, because HONO was not measured during the field campaign, future field experiments will be needed to determine whether the OBM-based predictions of high HONO concentrations in the early morning in Hong Kong area and the resultant enhancement in early morning $\mathrm{OH}$ production rates are appropriate.

\subsubsection{Relative incremental reactivity}

RIRs on 7 November: Fig. 13a-b shows the calculated RIRs for $\mathrm{AHC}, \mathrm{BHC}, \mathrm{CO}, \mathrm{NO}_{\mathrm{x}}$, and each $\mathrm{AHC}$ subgroup at each site on 7 November, and Fig. 14a-b shows the area-averaged RIRs for each precursor group and subgroup. The AHC group shows by far the highest RIR, meaning that $\mathrm{AHC}$ is the most important group in producing $\mathrm{O}_{3}$. BHC has a significant RIR at TM, the most rural site, but even here AHC has a much larger RIR. Not surprisingly (in light of the reactivity analysis presented in Sect. 3.1) R-AROM has the largest RIR among the AHC sub-groups.

The RIR for $\mathrm{NO}_{\mathrm{x}}$ is negative at all sites except $\mathrm{TO}$ where it is essentially zero (Fig. 13a), and the area-averaged RIR (the ozone-production weighted average at the five sites, see Cardelino and Chameides (1995) for the method of its calculation) for $\mathrm{NO}_{\mathrm{x}}$ is also negative (Fig. 14a). This negative RIR for $\mathrm{NO}_{\mathrm{x}}$ is the result of titration and radical scavenging due to the relatively high NO concentrations that were typically encountered at the sites during the field campaign. The results suggest that $\mathrm{O}_{3}$ photochemistry is strongly VOClimited throughout the Hong Kong area, and that initial reductions in $\mathrm{NO}_{\mathrm{x}}$ emissions in the area would actually lead to local $\mathrm{O}_{3}$ enhancements. The standard error $\sigma$ of the means in the area-averaged RIRs tends to be relatively small when compared to the RIRs themselves (Fig. 14a and b). This suggests that, at least from a statistical point of view, the RIR functions calculated here are robust.

RIRs at TO: The calculated RIRs for the major $\mathrm{O}_{3}$ precursor groups at TO on the episode days with VOC data generally confirm the results obtained from the other sites for the 7 November episode. AHC is the dominant precursor group with largest RIRs, and, among the AHCs, R-AROM dominate (not shown). On all days except 9 October the RIR for $\mathrm{NO}_{\mathrm{x}}$ was negative, and thus $\mathrm{NO}_{\mathrm{x}}$ tended to suppress $\mathrm{O}_{3}$ production on most of the episode days. The anomalous result for 9 October can be attributed to the fact that the NO concentrations were lower than on other episode days; the maximum NO concentration on 9 October was only 5.5 ppbv, compared to maxima of 7.6-95.4 ppbv on other days (Fig. 1).
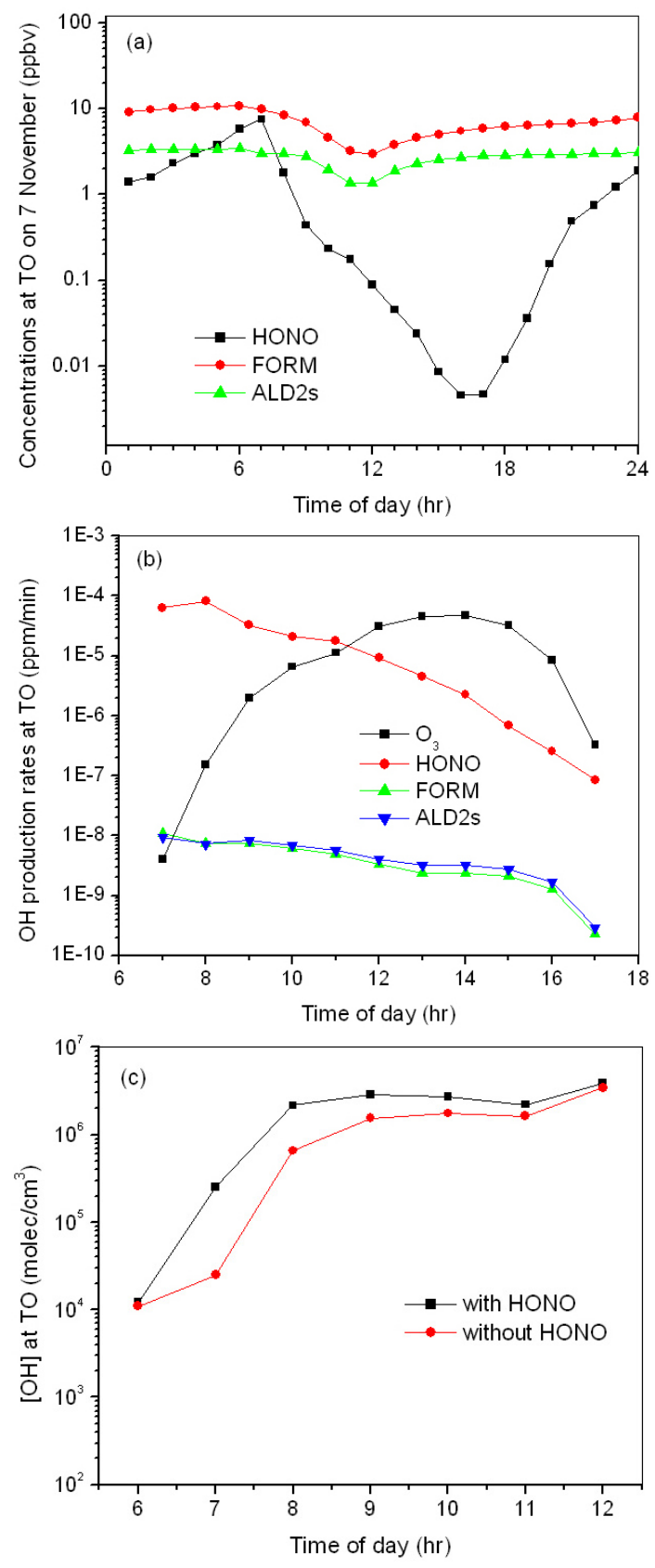

Fig. 12. (a) OBM-calculated concentrations of HONO, formaldehyde and higher aldehydes at Tai $\mathrm{O}$ on 7 November 2002; (b): OBM-calculated $\mathrm{OH}$ radical production rates from the photolysis of $\mathrm{O}_{3}, \mathrm{HONO}$, formaldehyde and higher aldehydes at Tai $\mathrm{O}$ on 7 November 2002; (c): Comparison of OBM-calculated OH concentrations at Tai $\mathrm{O}$ on 7 November 2002 with (black line) and without (red line) inclusion of early-morning HONO and aldehydes. Note the different time scales for the $\mathrm{x}$-axis.

It is worth noting that the conclusion of the VOC limited chemistry based on OBM calculations is also supported by the result inferred from the scatter plot of afternoon $\mathrm{O}_{3}$ 

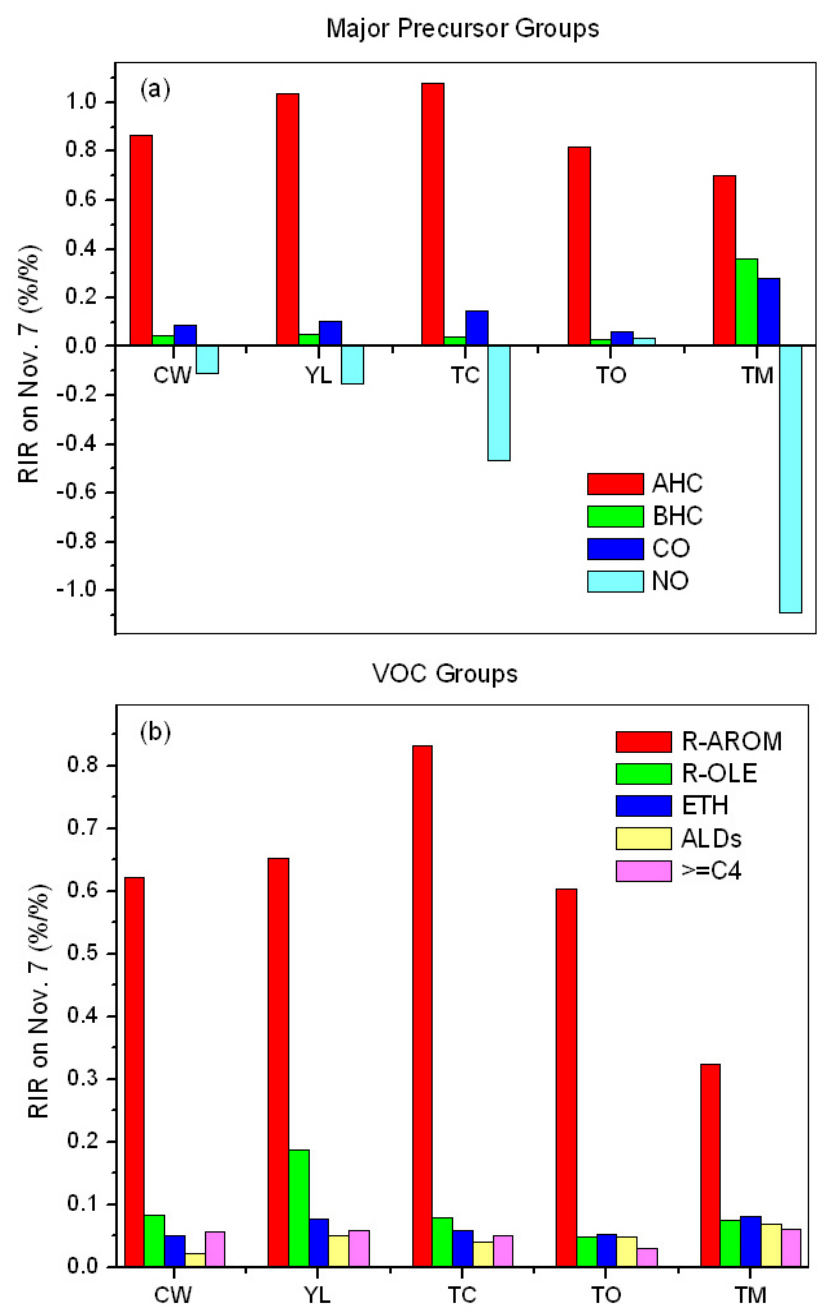

Fig. 13. Calculated RIRs for various major $\mathrm{O}_{3}$ precursor (a) groups and (b) subgroups at all five sites on 7 November 2002. The method by which RIR was estimated is shown in the text.

versus $\mathrm{NO}_{\mathrm{y}}$ at Tai $\mathrm{O}$ (figure not shown) which shows that the data points fall in the VOC-limited regime as suggested by Sillman and He (2002).

Sensitivity of RIRs to Model Uncertainties and Model Inputs: there are a large number of input parameters and model formulations in the OBM that are uncertain and add uncertainty to the RIR-functions calculated by the OBM. However, we have carried out sensitivity studies on the input concentrations of VOC, CO and NO. The formulations include both $+10 \%$ and $-10 \%$ of the change in the precursor's concentrations in the calculation of RIRs. In all cases, the major results were essentially the same. For example, we compared the RIRs obtained with the standard version of the OBM using diurnal profiles for VOC species (Sect. 3.2.2) with OBM results obtained with constant VOC concentrations as a function of time of day. While differences between the two cal-

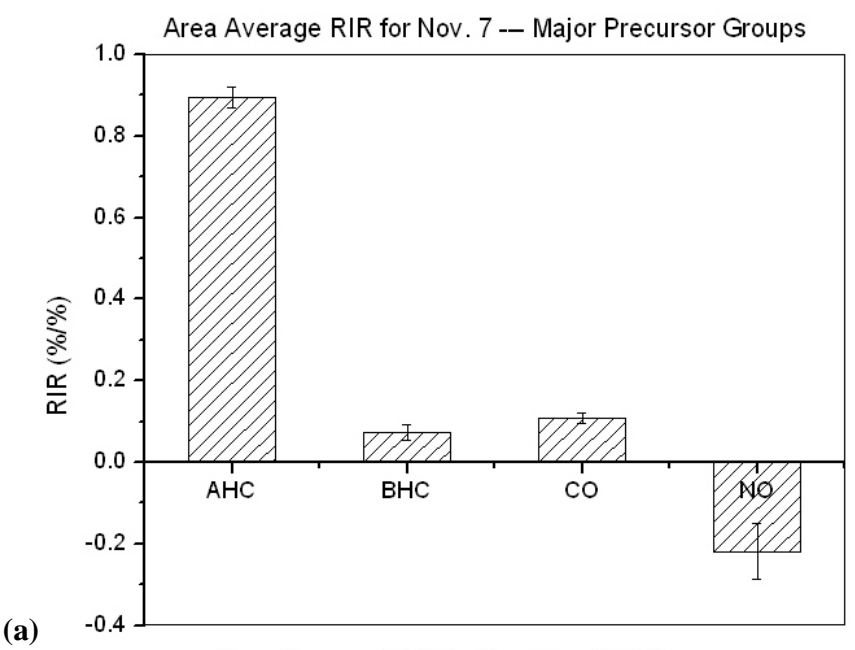

(a)

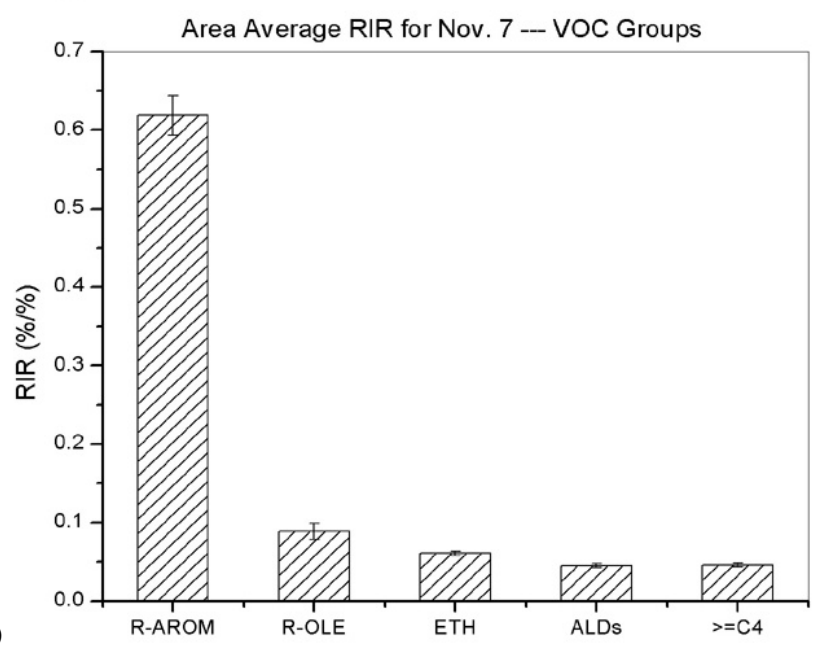

Fig. 14. Calculated area-averaged RIR and $\sigma$, the standard error of the means for various major $\mathrm{O}_{3}$ precursor (a) groups and (b) subgroups on 7 November 2002.

culations were obtained, the essential results are the same; i.e., the RIRs for AHC are large and positive and the RIRs for $\mathrm{NO}_{\mathrm{x}}$ are negative at the four EPD sites and small at TO. However for a detailed examination of photochemical processes, hourly data on VOCs would be desirable.

We also examined the sensitivity of the OBM results to the methods used to calculate both the inputs into the OBM and the RIR functions. In the standard model, the hourlyaveraged concentrations input into the model are arithmetic means of the high-resolution data collected at the sites. The RIRs were calculated from the difference in the net $\mathrm{O}_{3}$ production for the observed concentrations and for a $-10 \%$ of change in a precursor's concentrations. Using geometric means of high-resolution concentrations of $\mathrm{CO}$ and $\mathrm{NO}$ and using a $+10 \%$ change in a precursor's concentrations, our results were unchanged. 
Applicability of the Autumn Results: The findings that the $\mathrm{O}_{3}$ photochemistry in the Hong Kong area is strongly VOClimited and dominated by anthropogenic VOCs, especially reactive aromatics, are robustly supported by data that were gathered during one autumn. A comparison with the results from a similar analysis of summer episodes observed at Tai $\mathrm{O}$ and at an inland PRD site (Wan Qing Sha) suggests that these conclusions generally hold for inland PRD sites during a majority of summer episodes, although natural HCs could play an important role during summer at Tai $\mathrm{O}$ (So and Wang, manuscript in preparation). Undoubtedly, analysis of data from other areas in the PRD would provide more insights into $\mathrm{O}_{3}$ photochemistry for the whole PRD region.

It should also be pointed out that while addressing some problems associated with the EBMs, OBM has its own limitations as discussed in Cardelino and Chameides (1995). It uses surface/point measurements, thus the result lacks spatial representation; OBM cannot predict exactly how much reduction in emission is needed to bring an area into compliance. However, in view of difficulty in obtaining accurate emission inventories in the PRD (and other urban and industrial regions of China) due to the existence of complex emission sources, OBM results based on high-quality atmospheric observations provide valuable insights into the key species that control the formation of ozone in the region.

\section{Conclusions}

Various observation-based approaches were used to analyze the relationships between ozone, ozone precursors, and cross-border transport during ozone episodes observed in the Hong Kong area.

Local emissions from Hong Kong as well as emissions from Guangdong Province appear to act in concert or individually in fostering $\mathrm{O}_{3}$ pollution episodes in Hong Kong. Between $50-100 \%$ of the $\mathrm{O}_{3}$ increase observed in Hong Kong during $\mathrm{O}_{3}$-pollution episodes can be explained by photochemical generation within the Hong Kong area. In addition, HONO (and to a lesser extent aldehydes) was calculated to play a critical role in local $\mathrm{O}_{3}$ generation, provided that HONO was present at the concentrations derived from OBM calculations.

The reactivity of the VOCs is dominated by anthropogenic VOCs, with VOCs from natural or biogenic sources making a minor contribution during fall, when this field study was conducted. Of the anthropogenic VOCs, reactive aromatics dominate, of which xylenes and toluene are the most important.

The formation of $\mathrm{O}_{3}$ throughout much of the Hong Kong area is limited by VOCs, and high NO concentrations suppress $\mathrm{O}_{3}$ production in much of the Hong Kong area. Ozone sensitivity to VOCs is dominated by the contribution from reactive aromatics.
Our analyses were on measurements at certain locales and during certain time period. Therefore, the data that form the basis for our analyses are spatially and temporally limited. Further studies are needed to confirm and quantify the role of HONO in early morning chemistry. While a preliminary comparison with the results obtained during summer both in Hong Kong and at a PRD inland site suggests that the conclusions obtained in the present study generally hold, analysis of data collected from more areas in the PRD would be valuable to characterize additional areas of significant $\mathrm{O}_{3}$ pollution and to determine the relative roles of anthropogenic and natural VOCs and the VOC- versus $\mathrm{NO}_{\mathrm{x}}$-limitations of the $\mathrm{O}_{3}$ photochemistry.

Acknowledgements. This work was funded by Hong Kong Jockey Club Charities Trust, Castle Peak Power Co. Ltd., the Environmental Protection Department of the Hong Kong Special Administrative Region, and Shell Hong Kong Ltd., through Civic Exchange. Additional support to the PolyU team was provided by the Research Grants Council of the Hong Kong Special Administrative Region (Project No. PolyU 5144/04E). We thank C. Loh and C. S. Kiang for coordinating the Pilot Study Project, Kylie Ubergang for providing various supports to the project team, S. Poon for contributing to field measurements at Tai $\mathrm{O}$, and I. Simpson for giving helpful comments on this manuscript. We thank S. Sillman and an anonymous referee for their valuable comments and suggestions. MM5 and HYSPLIT models were made available by NCAR and NOAA Air Resources Laboratory (ARL), respectively.

Edited by: M. G. Lawrence

\section{References}

Alicke, B., Platt, U., and Stutz, J.: Impact of nitrous acid photolysis on the total hydroxyl radical budget during the Limitation of Oxidant Production/Pianura Padana Produzione di Ozono study in Milan, J. Geophys. Res., 107(D22), 8196, doi:10.1029/2000JD000075, 2002.

Alicke, B., Geyer, A., Hofzumahaus, A., Holland, F., Konrad, S., Patz, H. W., Schafer, J., Stutz, J., Volz-Thomas, A., and Platt, U.: $\mathrm{OH}$ formation by HONO photolysis during the BERLIOZ experiment, J. Geophys. Res., 108(D4), 8247, doi:10.1029/2001JD000579, 2003.

Blanchard, C. L., Lurmann, F. W., Roth, P. M., Jeffries, H. E., and Korc, M.: The use of ambient data to corroborate analyses of ozone control strategies, Atmos. Environ., 33, 369-381, 1999.

Calvert, J. G.: Test of the theory of ozone generation in Los Angeles atmosphere, Environ. Sci. Technol., 10, 248-262, 1976.

Cardelino, C.: Daily variability of motor vehicle emissions derived from traffic counter data, J. Air Waste Manage. Assoc., 48, 637645, 1998.

Cardelino, C. and Chameides, W. L.: An observation-based model for analyzing ozone precursor relationships in the urban atmosphere, J. Air Waste Manage. Assoc., 45, 161-180, 1995.

Cardelino, C. and Chameides, W. L.: The application of data from photochemical assessment monitoring stations to the 
observation-based model, Atmos. Environ., 34, 2325-2332, 2000.

CH2M HILL (China) Limited: Final report: agreement No. CE 106/98: Study of Air Quality in the Pearl River Delta Region, April 2002.

Chameides, W. L., Davis, D. D., Bradshaw, J., Sandholm, S., Rodgers, M., Baum, B., Ridley, B., Madronich, S., Carroll, M. A., Gregory, G., Schiff, H. I., Hastie, D. R., Torres, A., and Condon, E.: Observed and model-calculated $\mathrm{NO}_{2}$ : $\mathrm{NO}$ ratios in tropospheric air sampled during the NASA GTE/CITE 2 field study, J. Geophys. Res., 95, 10 235-10 247, 1990.

Chameides, W. L., Fehsenfeld, F., Rodgers, M. O., Cardelino, C., Martinez, J., Parrish, J. D., Lonneman, W., Lawson, D. R., Rasmussen, R. A., Zimmerman, P., Greenberg, J., Middleton, P., and Wang, T.: Ozone precursor relationships in the ambient atmosphere, J. Geophys. Res., 97, 6037-6055, 1992.

Cheung, H. C., Wang, T., Baumann, K., and Guo, H.: Influence of regional pollution outflow on the concentrations of fine particulate matter and visibility in the coastal area of southern China, Atmos. Environ., 39, 6463-6474, 2005.

Colman, J. J., Swanson, A. L., Meinardi, S., Sive, B. C., Blake, D. R., and Rowland, F. S.: Description of the analysis of a wide range of volatile organic compounds in whole air samples collected during PEM-Tropics A and B, Anal. Chem., 73, 37233731, 2001.

Ding, A., Wang, T., Zhao, M., Wang, T. J., and Li, Z. K.: Simulation of sea-land breezes and a discussion of their implications on the transport of air pollution during a multi-day ozone episode in the Pearl River Delta of China, Atmos. Environ., 38, 6737-6750, 2004.

Finlayson-Pitts, B. J., Wingen, L. M., Sumner, A. L., Syomin, D., and Ramazan, K. A.: The heterogeneous hydrolysis of $\mathrm{NO}_{2}$ in laboratory systems and in outdoor and indoor atmospheres: An integrated mechanism, Phys. Chem. Chem. Phys., 5, 223-242, 2003.

Geron, C. D., Guenther, A. B., and Pierce, T. E.: An improved model for estimating emissions of volatile organic compounds from forests in the eastern United States, J. Geophys. Res., 99, 12773-12 791, 1994.

Guenther, A., Geron, C., Pierce, T., Lamb, B., Harley, P., and Fall, R.: Natural emissions of non-methane volatile organic compounds, carbon monoxide, and oxides of nitrogen from North America, Atmos. Environ., 34, 2205-2230, 2000.

Hanna, S. R., Moore, G. E., and Fernau, M. E.: Evaluation of photochemical grid models (UAM-IV, UAM-V, and the ROM/UAMIV couple) using data from the Lake Michigan Ozone Study (LMOS), Atmos. Environ., 30, 3265-3279, 1996.

Harrison, R. M., Peak, J. D., and Collins, G. M.: Tropospheric cycle of nitrous acid, J. Geophys. Res., 101, 14 429-14 439, 1996.

Hidy, G.: Ozone process insights from field experiments - Part I. NARSTO Critical Review Papers Special Issue, Atmos. Environ., 34, 2001-2022, 2000.

Holzworth, G. C.: Mixing depths, wind speeds and air pollution potential for selected locations in the United States, J. Appl. Meteorol., 6, 1039-1044, 1967.

Hu, M., Zhou, F., Shao, K., Zhang, Y., Tang, X., and Slanina, J.: Diurnal variations of aerosol chemical compositions and related gaseous pollutants in Beijing and Guangzhou, J. Environ. Sci. Heal. A, A37(4), 479-488, 2002.
Jacobson, M. Z.: Fundamentals of Atmospheric Modeling, Cambridge University Press, 385-393, 1999.

Jenkin, M. I., Cox, R. A., and Williams, D. J.: Laboratory studies of the kinetics of formation of nitrous acid from the thermal reaction of nitrogen dioxide and water vapor, Atmos. Environ., 22, 487498, 1988.

Kok, G. L., Lind, J. A., and Fang, M.: An airborne study of air quality around the Hong Kong Territory, J. Geophys. Res., 102, 19043-19057, 1997.

Kuklin, A. and Seinfeld, J. H.: Emissions reductions needed to meet the standard for ozone in Southern California: effect of boundary conditions, J. Air Waste Manage. Assoc., 45, 899-901, 1995.

Kumar, N. and Russell, A. G.: Comparing prognostic and diagnostic meteorological fields and their impacts on photochemical air quality modeling, Atmos. Environ., 30, 1989-2010, 1996.

McKeen, S. A., Mount, G., Eisele, F., Williams, E., Harder, J., Coldan, P., Kuster, W., Liu, S. C., Baumann, K., Tanner, D., Fried, A., Sewell, S, Cantrell, C., and Shetter, R.: Photochemical modeling of hydroxyl and its relationship to other species during the Tropospheric OH Photochemistry Experiment, J. Geophys. Res., 96, 6467-6493., 1997.

National Academy of Sciences (NAS): Rethinking the ozone problem in urban and regional air pollution, Natl. Acad. Press, Washington, D.C., 1991.

Oreske, N., Shrader-Frechette, K., and Belitz, K.: Verification, validation, and confirmation of numerical models in the Earth sciences, Science, 263, 641-646, 1994.

Parrish, D. D., Trainer, M., Williams, E. J., Fahey, D. W., Hubler, G., Eubank, C. S., Liu, S. C., Murphy, P. C., Albritton, D. L., and Fehsenfeld, F. C.: Measurements of the NO-O3 photostationary state at Niwot Ridge, Colorado, J. Geophys. Res., 91, 5361-5370, 1986.

Pierson, W. R., Gertler, A. W., and Bradow, R. L.: Comparison of the SCAQS tunnel study with other on-road vehicle emission data, J. Air Waste Manage. Assoc., 40, 1495-1504, 1990.

Russell, A. G. and Dennis, R. L.: Critical review of photochemical models and modeling. NARSTO Critical Review Papers Special Issue, Atmos. Environ., 34, 2283-2324, 2000.

Seinfeld, J. H. and Pandis, S. N.: Atmospheric Chemistry and Physics: From Air Pollution to Climate Change, John Wiley \& Sons, Inc., New York, 1997.

Sillman, S.: The use of $\mathrm{NO}_{\mathrm{y}}, \mathrm{H}_{2} \mathrm{O}_{2}$ and $\mathrm{HNO}_{3}$ as indicators for $\mathrm{O}_{3}-\mathrm{NO}_{\mathrm{x}}-\mathrm{ROG}$ sensitivity in urban locations, J. Geophys. Res., 100, 14 175-14 188, 1995.

Sillman, S. and He, D.: Some theoretical results concerning $\mathrm{O}_{3}-$ $\mathrm{NO}_{\mathrm{x}}$-VOC chemistry and $\mathrm{NO}_{\mathrm{x}}$-VOC indicators, J. Geophys. Res., 107, 4659, doi:10.1029/2001JD001123, 2002.

Sillman, S., He, D., Cardelino, C., and Imhoff, R. E.: The use of photochemical indicators to evaluate ozone- $\mathrm{NO}_{\mathrm{x}}$-hydrocarbon sensitivity: Case studies from Atlanta, New York and Los Angeles, J. Air Waste Manage. Assoc., 47, 642-652, 1997.

Simpson, D.: Biogenic emissions in Europe, 2, implications for ozone control strategies, J. Geophys. Res., 100, 22 891-22 906, 1995.

Simpson, I. J., Wang, T., Guo, H., Kwok, Y. H., Flocke, F., Atlas, E., Meinardi, S., Rowland, F. S., and Blake, D. R.: Longterm atmospheric measurements of $\mathrm{C}_{1}-\mathrm{C}_{5}$ alkyl nitrates in the Pearl River Delta region of southeast China, Atmos. Environ., 40, 1619-1632, 2006. 
Streets, D. G., Bond, T. C., Carmichael, G. R., Fernandes, S. D., Fu, Q., He, D., Klimont, Z., Nelson, S. M., Tsai, N. Y., Wang, M. Q., Woo, J.-H., and Yarber, K. F.: An inventory of gaseous and primary aerosol emissions in Asia in the year 2000, J. Geophys. Res., 108(D21), 8809, doi:10.1029/2002JD003093, 2003.

Tan, Q., Chameides, W. L., Streets, D., Wang, T., Xu, J., Bergin, M., and Woo, J.: An evaluation of TRACE-P emission inventories from China using a regional model and chemical measurements, J. Geophys. Res., 109(D22), D22305, doi:10.1029/2004JD 005071, 2004.

Wang. T.: Study of visibility reduction and its causes in Hong Kong, Final report to the Environmental Protection Department, Hong Kong Special Administrative Region, available at http://www.epd.gov.hk/epd/english/environmentinhk/air/ studyrpts/air_studyrpts.html, 2003.

Wang, T., Wu, Y. Y, Cheung, T. F., and Lam, K. S.: A study of surface ozone and the relation to complex wind flow in Hong Kong, Atmos. Environ., 35, 3203-3215, 2001 a.
Wang, T., Cheung, V. T. F., Lam, K. S., Kok, G. L., and Harris, J. M.: The characteristics of ozone and related compounds in the boundary layer of the South China coast: temporal and vertical variations during autumn season, Atmos. Environ., 35, 2735 2746, 2001b.

Wang, T. and Kwok, Y. H. J.: Measurement and analysis of a multiday photochemical smog episode in Pearl River Delta of China, J. Appl. Meteorol., 42, 404-416, 2003.

Wang, T., Poon, C. N., Kwok, Y. H., and Li, Y. S.: Characterizing the temporal variability and emission pattern of pollution plumes in the Pearl River Delta of China, Atmos. Environ., 37, 35393550, 2003.

Wang, T., Guo, H., Blake, D. R., Kwok, Y. H., Simpson, I. J., and Li, Y. S.: Measurements of Trace Gases in the Inflow of South China Sea Background Air and Outflow of Regional Pollution at Tai O, Southern China, J. Atmos. Chem., 52, 295-317, 2005.

Zhang, J., Chameides, W. L., Wang, T., and Kiang, C. S.: Groundlevel ozone pollution in Hong Kong, Final report. Civic Exchange, Hong Kong, available at http://www.civic-exchange.org/ website, 2004. 